
Invited Feature Article

\title{
2 Chiral Photochemical Scissors: Toward Site Specific Cleavage of Proteins with Light
}

4 Bobbi Stromer ${ }^{1}$, Melissa Limbacher ${ }^{1}$, Dhanya T. Jayaram ${ }^{2}$, Sudarat Yenjai ${ }^{3}$, Ruma Chowdhury ${ }^{1}$, 5 Apinya Buranaprapuk ${ }^{3}$, Danaboyina Ramaiah ${ }^{4}$, and Challa V. Kumar ${ }^{1,5^{*}}$

$7{ }^{1}$ Department of Chemistry, 55 N. Eagleville Road, U-3060, University of Connecticut, Storrs, 8 Connecticut 06269-3060

$9{ }^{2}$ CSIR-National Institute for Interdisciplinary Science and Technology (CSIR-NIIST), 10 Thiruvananthapuram, 695019, India

$11{ }^{3}$ Department of Chemistry, Srinakarinwirot University, Sukhumvit 23, Bangkok 10110, Thailand

$12{ }^{4}$ CSIR-North East Institute of Science and Technology (CSIR-NEIST), Jorhat, 785006, India

$13{ }^{5}$ Department of Molecular and Cellular Biology, 91 N. Eagleville Road, U-3125, University of 14 Connecticut, Storrs Connecticut 06269-3125

15 *Corresponding Author: Challa Vijaya Kumar, challa.kumar@uconn.edu

16 keywords

17 Pyrene, Squaraine, Co(III)hexamine, serum albumin, avidin, lysozyme, photocleavage, flash 18 photolysis, circular dichroism, fluorescence, sequencing, phenylalanine, SDS/PAGE, steady state, 19 quantum yield, docking 


\section{Table of Contents}

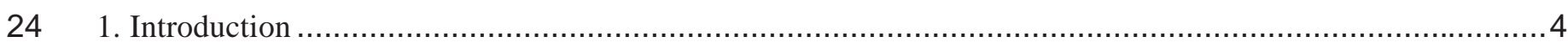

$25 \quad 2$. Rational design of the protein photocleavage reagents ..............................................................

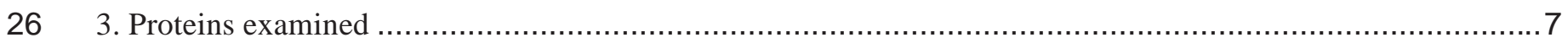

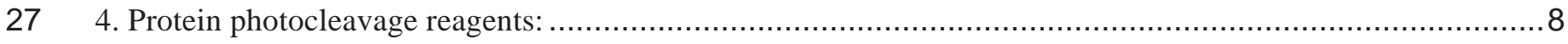

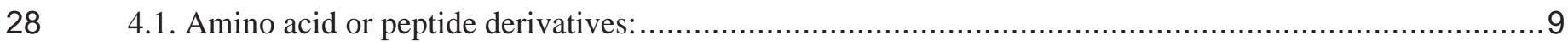

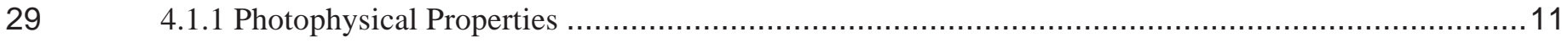

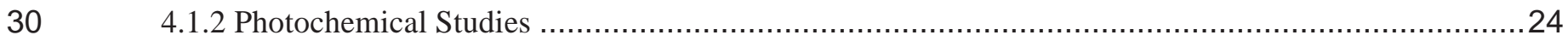

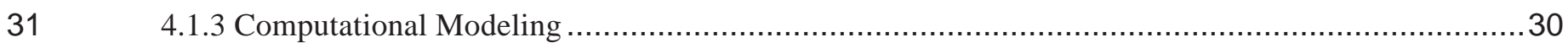

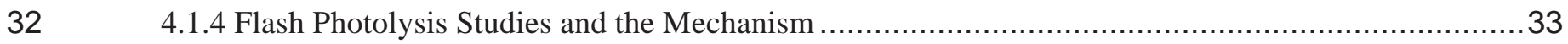

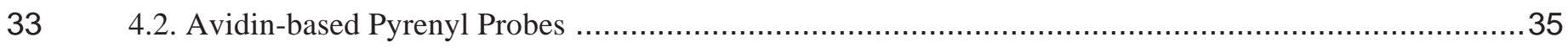

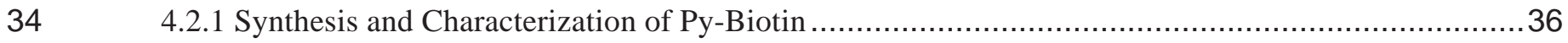

$35 \quad 4.2 .2$ Photophysical studies of Py-Biotin with Avidin ....................................................... 36

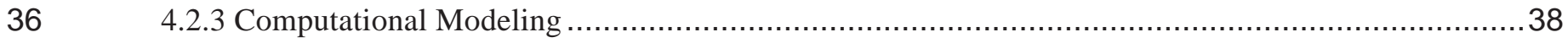

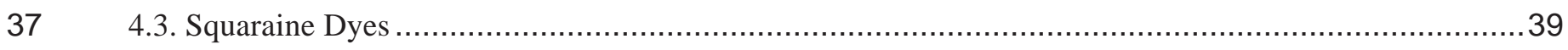

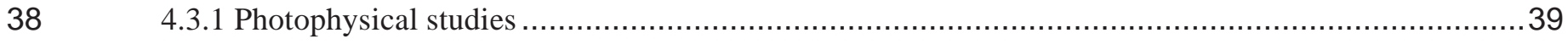

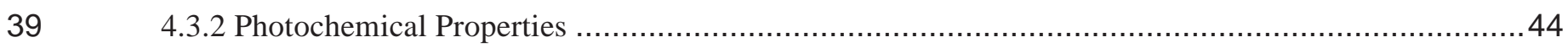

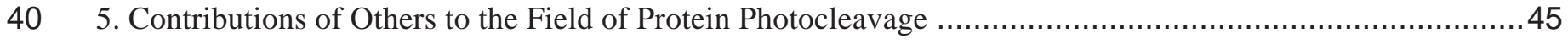

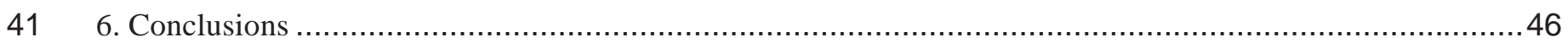

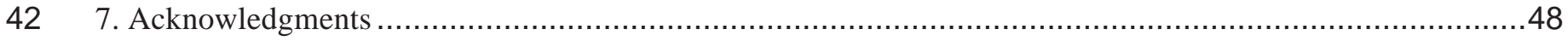




\section{Abstract:}

48 A powerful strategy to photocleave the protein backbone at a single site, developed over nearly two 49 decades, is described here. The remarkable ability to target one or even a couple of sites on a large 50 protein with a small molecule, under photochemical control, is a considerable challenge. Systematic 51 modification of the structure of the photoreagent provides valuable information on the binding site recognition as well as the mechanism of the photocleavage reaction. Some factors that impact the photocleavage reaction include the exact location of the probe binding site on the protein, conformations of the bound probe, protein size, functional groups present on the probe that ean interact with the protein surroundings either in a favorable or unfavorable manner, overall charge on the photoreagent, and photophysical/photochemical properties of the probe. The protein photocleavage studies were preceded by detailed binding studies by a variety of spectroscopic methods. Methods as simple as absorption and fluorescence spectroscopies or more sophisticated circular dichroism spectroscopy were used. Conclusions that are most consistent with the binding data indicated a single binding site on most proteins, irrespective of the probe or the protein, with only one exception noted so far. Such high selectivity for targeting a binding site on a biomolecule by a small molecule is remarkable. Photocleavage studies and laser flash photolysis studies were used to probe the photochemical peptide bond cleavage reactions, which indicated the important role of aromatic cation radicals in the mechanistic path. Our work focused mainly on few generic proteins serum albumin, 65 lysozyme, and avidin; but may be extended to other proteins with appropriate modifications. This article strives to provide some guidance on such design strategies for other proteins or other photoreagents. Molecular modeling studies clearly supported our conclusions and the methods described here could be useful in a rational design of novel photoreagents to target desired sites on 69 proteins in future studies. 


\section{Introduction}

Photochemical reactions provide exquisite control over the initiation and termination of chemical reactions, where the key reagent (light) vanishes before the workup of the reaction mixture. Therefore, light initiated protein-cleavage reaction methodology appealed to us, nearly two decades ago. ${ }^{1}$ Reagents that cleave proteins upon activation with light were unknown at that time, and our group was the first to demonstrate that rationally designed organic molecules could cleave the peptide backbones of large proteins at a single site (site specific). The initial approach and the early methods have been modified to include inorganic photo reagents, which also demonstrated specificity or high selectivity for the photocleavage of proteins, sometimes in high yields, approaching $60 \%$. $^{2}$ One interesting feature of these artificial photo proteases was that the newly produced $\mathrm{N}$-terminus or the Cterminus (in some cases) of the product peptide fragments has been amenable to standard biochemical sequencing methods. ${ }^{3,7}$ Therefore, these reactions provided a useful tool for making smaller fragments from larger proteins that can be sequenced. This article provides an account of these investigations, challenges, failures, and specific approaches as well as the current status of this area of exciting protein photochemistry.

Protein photocleavage is also an interesting tool to footprint ligand binding sites on large biological structures such as protein/DNA complexes or protein/protein complexes or enzymes bound to solid surfaces. ${ }^{3,45}$ Such very large biological/chemical structures are not readily amenable to current approaches of biochemical methodologies such as cryo TEM or protein mass spectrometry ${ }^{2,3,6}$ Protein photocleavage studies can, therefore, provide valuable structural data to better understand the molecular basis for recognition in the solution phase, under ambient conditions. Structures of biomolecules in the solution phase are often more relevant to functional biological systems where bimolecular or multimeric structures are important. This understanding in liquid phase could be important to manipulate and control biological processes such as cell communication, cell adhesion, cell motion, gene expression, and the fight against antibiotic resistance. ${ }^{7}$

An unexpected application that emerged out of our photochemical studies is the design, construction and testing of artificial light antenna systems based on ordinary proteins. ${ }^{8}$ This strategy arose from the conclusion that organic ligands can be designed to bind to discrete sites on selected proteins, thus allowing us to assemble large numbers of chromophores in proteins at defined distances. This also allowed for the control of specific orientation of the chromophore and tuning of the affinities, 
100 while suppressing chromophore aggregation and undesirable excited state annihilation or quenching. 101 These molecular assemblies made of dyes and proteins functioned as efficient visible light harvesting 102 antennas. $^{9}$

\section{Rational design of the protein photocleavage reagents}

Site specific photocleavage (cleavage at a single site) of proteins can be achieved by directing the reagent to a specific site on the target protein and subsequent photoactivation to cleave the peptide backbone. Our experience showed that even moderate binding affinities and moderate photochemical quantum yields are sufficient to achieve this goal. However, the design of the reagent is critical in achieving binding at a particular site on the protein, which could endow specificity for the photocleavage reaction. This unexpected outcome was due to the fact that the binding sites in proteins are highly crowded for moderately sized photoreagents, and the excited state or the reactive intermediate does not have necessary freedom to explore different parts of the binding site.

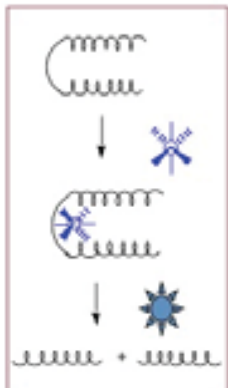

A. B.

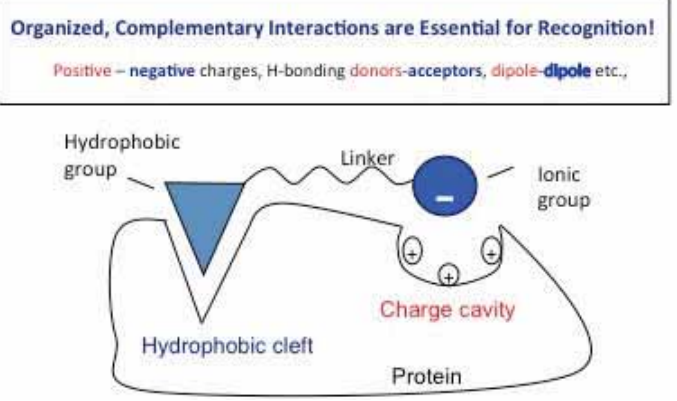

C.

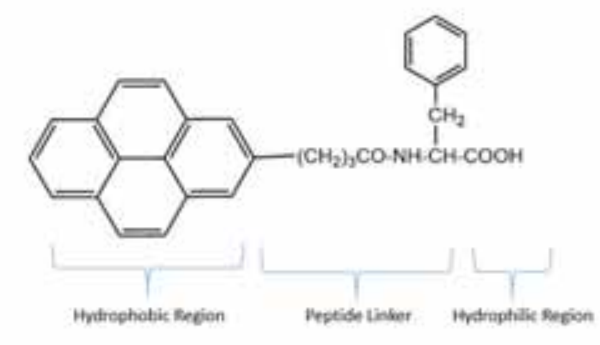

Scheme 1. A. Chiral protein scissors that bind to protein and cleave on irradiation at specific sites. $B$. General strategy for photoreagent design. C. Pyrenyl photocleaving agent, Py-(L or D)-Phe. Scheme A reproduced with permission from Langmuir.

The photoreagent design is, therefore, critical and should take into account structural features of the photoreagent such as size, shape, H-bonding groups, dipoles, charged groups and chirality for proper interaction with the binding site on the target protein (Scheme 1A, B). These features allow discrimination of a given binding site by the reagent against other possible sites on the target protein and could reduce the number of possible binding sites. Thermodynamically, this would drive binding selectivity/specificity, and photoexcitation of the protein-bound reagent, under these conditions, to produce fewer cleavage sites than if the binding occurs at multiple sites. Our goal in the early studies 
124 was to bind the photoreagent to a single site on a given target protein, among multiple possible binding 125 sites. Modern computational modeling using powerful docking algorithms have made excellent 126 progress in this aspect, and docking studies matched well with the cleavage sites observed for a few 127 proteins and a handful of photocleavage reagents. ${ }^{2}$ While this outcome is very satisfying and 128 supportive of the methodology described in this article, the design of a new reagent to cleave at a 129 desired site on a target protein is still a fundamental, unsolved problem.

Therefore, a qualitative approach based on the principle of 'Complementarity' has been explored in this article. Our main assumption is that the ligand structure, shape, and interaction sites should 'Complement' those at the binding site on the target protein to achieve the lowest free energy bound state (Scheme 1). Our initial studies were directed to evaluate unique binding sites on common proteins such as serum albumin, lysozyme, and avidin. Our ligand design included: (1) a hydrophobic chromophore which is to be buried in the non-polar interior of a protein; (2) a hydrophilic anchor group that would prefer to reside in the aqueous medium near the protein/water interface, and (3) a suitable linker connecting the polar and nonpolar groups of the reagent so that the two regions can be separated well enough to satisfy the requirements of the binding site (Scheme 1B).

These principles rose out of the observation that the interior of most water-soluble proteins are fairly lipophilic while their exterior is strongly hydrophilic (oil drop model of a protein). ${ }^{10}$ With this combination of contrasting interactions (a hydrophobic group and a hydrophilic group separated by a linker) it would be possible to direct the photoreagent to specific sites on the protein at the solvent/protein interface, with the most favorable binding site complementing the specific interactions supported by the photoreagent. For example, a positively charged hydrophilic group on the reagent would prefer to reside next to an anionic side chain at the binding site. Similarly, the hydrogen bonding donor and acceptor sites of the binding site would complement that on the reagent, at optimal distances so that the free energy of the system would be reduced. These multiple prerequisites enhance the binding selectivity of the probe and hence, increase the number of these interactions, enhancing the selectivity for binding. Highly selective binding could in turn improve selectivity for subsequent protein photocleavage. This approach of 'Complementarity' has been very successful and provided a powerful algorithm to direct ligands to a single site even on a very large protein that has multiple, known, ligand binding sites. ${ }^{2}$ 
The next important step in the design was to include an appropriate chromophore which would absorb the photon of desired wavelength and initiate the photoreaction that would ultimately result in peptide bond cleavage at the reagent binding site. We tested both organic ${ }^{1-7}$ as well as inorganic ${ }^{11}$ chromophores to initiate the protein photocleavage reactions. For example, the pyrene chromophore served as the hydrophobic group to anchor the probe in the protein interior (Scheme 1C). A short peptide was chosen to be the linker connecting the chromophore to the polar/charged group (Scheme 1B,C). The peptide linker would complement interactions with the peptide chain of the protein and it is expected to promote photoreagent binding to the protein via hydrogen bonding interactions.

The use of a positively charged Co(III) metal complex was envisioned as the polar group ligated to the C-terminus of the peptide linker of the photoreagent, in the above design, but initial studies were done without ligation of the metal complex. Thus, C-terminus of the peptide linker itself served as the polar group, and a redox metal complex served to sensitize the photo oxidation of the otherwise unreactive pyrene excited state of the probe. For example, $\mathrm{Co}(\mathrm{III})$ hexammine $(\mathrm{CoHA})$ and other Co(III) complexes are well known to quench pyrene excited state and produce the corresponding aryl radical cation. ${ }^{2,4,6}$ Our hypothesis was that the pyrene excited state has sufficient energy to sensitize the photo decomposition of $\mathrm{Co}(\mathrm{III})$ hexamine, and photo decomposition of CoHA is known to result in reactive $\mathrm{NH}_{2}$ radical. ${ }^{12}$ The central hypothesis was that the $\mathrm{NH}_{2}$ radical would abstract a hydrogen atom from the peptide backbone and ultimately lead to peptide bond cleavage, in a manner similar to CoHA photocleavage of the sugar phosphate backbone of double helical DNA. ${ }^{13}$ However, at that time none of the related protein photocleavage chemistry by $\mathrm{Co}(\mathrm{III})$ complexes was known. Thus, these hypotheses were considered high-risk-high-dividend studies.

Use of photons for protein cleavage allows for strict control over the initiation and termination of the reaction, which facilitates mechanistic studies via time-resolved methods. These are green reaction conditions where one of the reagents (light) disappears and simplifies the reaction workup.

The above interesting hypotheses were tested over the last two decades ${ }^{1-7,14,15,16}$, and lessons learned in this endeavor are enumerated below.

\section{Proteins examined}

Bovine Serum Albumin (BSA), avidin, and lysozyme are utilized in the experiments described below and extensions to other proteins are possible with appropriate modifications of the current methodology. BSA (Figure 1A) is a $65 \mathrm{kDa}$, major carrier protein of the circulatory system, and it 
transports lipids, metal ions, amino acids, hormones, and peptides. Most drugs entering the blood circulation encounter this protein, and therefore, BSA has been extensively studied for its interaction with small organic molecules, peptides and hormones. ${ }^{17} \mathrm{BSA}$ is a heart shaped protein made up of three homologous domains with multiple, major binding sites that support ligand binding via a multitude of hydrophobic, hydrogen bonding, and electrostatic interactions. ${ }^{18,19}$

188
A.

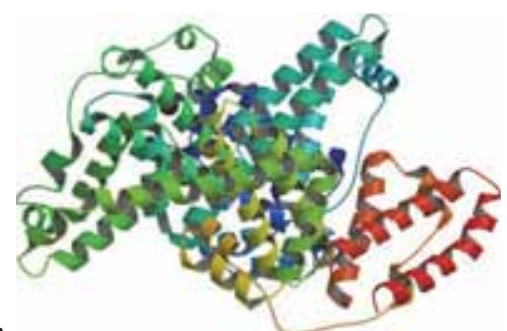

B.

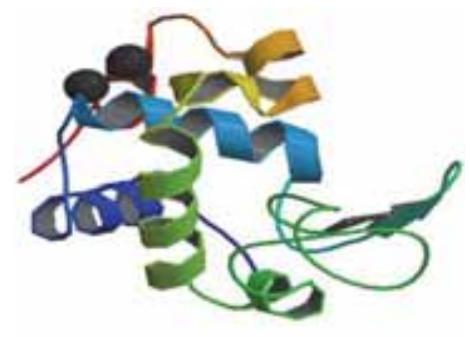

C.

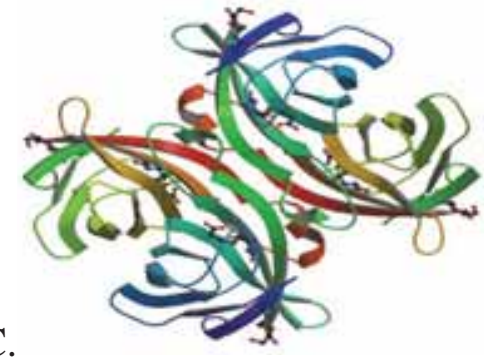

Figure 1: Structures of A) Bovine serum albumin (BSA) (PDB ID: 3VO3) ${ }^{20}$, B) Lysozyme (PDB ID: $1 D P X)^{21}$, and C) Avidin (PDB ID: 2AVI $)^{22}$ used for photocleavage studies in this article.

Lysozyme (Figure 1B) is a small (14.3 kDa), water soluble enzyme present in numerous biological fluids, including human tears. It is part of the innate immune system and it can hydrolyze and break down bacterial cell walls, especially gram positive bacteria. ${ }^{23}$ Lysozyme is the first enzyme to be crystalized and have its structure determined by X-ray diffraction. ${ }^{24}$ Avidin (Figure 1C) is a 60 $\mathrm{kDa}$ tetrameric glycoprotein that binds strongly to biotin with an affinity constant of $10^{15} \mathrm{M}^{-1}$, which is nearly as strong as a weak covalent bond. ${ }^{25}$ Avidin is made of four identical subunits, each of which can bind one biotin molecule. Biotin binding site is within the core of the eight stranded, antiparallel $\beta$-barrel that makes up each subunit. The strong binding of biotin is frequently exploited in avidinbiotin technology for biological assays. ${ }^{26}$

\section{Protein photocleavage reagents:}

A number of different classes of reagents were tested for protein photocleavage and these included four major classes: (A) amino acid or peptide derivatives, ${ }^{1-7}$ (B) avidin based reagents, ${ }^{5}(\mathrm{C})$ squaraine derivatives, ${ }^{27,28}$ (D) uranyl ions ${ }^{14}$ and (E) coordination metal complexes. ${ }^{11,15,16}$ Among these, only the first three systems are presented here, in that order. Design of each of these classes of reagents, their interactions with target proteins, and their photocleavage reactions will be discussed in 
some detail while providing an overview of a large body of work that appeared in the past decade. 208 Finally, flash photolysis studies that helped understand some of the initial details of the peptide 209 cleavage reaction are also presented.

210

211

212

213

214

215

216

217

218

219

220

221

222

223

224

225

226

227

228

229

230

\subsection{Amino acid or peptide derivatives:}

Pyrene chromophore was used as the hydrophobic moiety in the design of most of the photoreagents described here, and this choice has been based on the excellent photophysics of this well understood chromophore. ${ }^{29}$ Pyrene has a high extinction coefficient in the near UV region $(>40,0000$ $\mathrm{M}^{-1} \mathrm{~cm}^{-1}$ at $343 \mathrm{~nm}$ ) and a long lived singlet excited state (>200 ns). The high energy of the pyrenyl excited state can be harvested for photochemical reactions to cleave the peptide backbone. Covalent conjugation of the carboxyl group of 4(1-pyrene)butyric acid with the amine group of L-phenylalanine was done using the standard carbodiimide chemistry ${ }^{30}$ resulted in phenylalanine-4(1-pyrene) butyramide (Py-L-Phe) (Scheme 2). This was our first photoreagent tested for successful protein photocleavage.

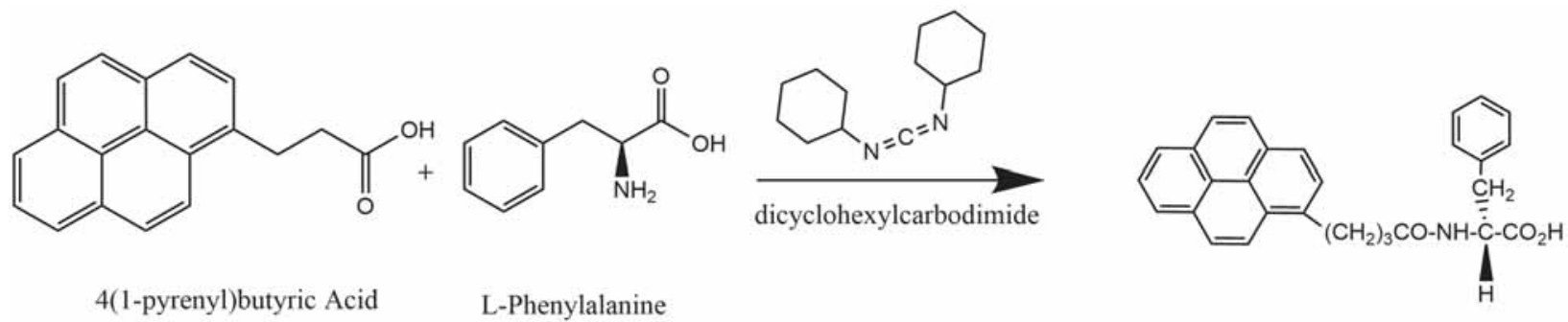

Scheme 2. Synthesis of photocleaving agent Py-L-Phe by linking the COOH group of 4(1pyrenyl)butyric acid with the amine function of L-phenylalanine (Phe) by the standard carbodiimide condensation chemistry. Many other amino acids or short peptides can also be used instead of Phe.

Our initial design included the 6-atom linker and the hydrophilic carboxyl group, as in Py-LPhe, which has a chiral center derived from L-phenylalanine (Scheme 2). Followed by the initial success with Py-L-Phe (described later), the linker length of the photoreagent was systematically tuned by inserting additional amino acid residues (Scheme 3). This variation resulted in a predictable increase in the distance of separation between the pyrenyl chromophore and the hydrophilic carboxyl group. In addition, we also tested logical variations on the amino acid studies of the linker to 
systematically test the role of the linker in the binding and photocleavage mechanism. Scheme 3 provides a quick overview of the Py-Phe analogs that have been examined in this report.
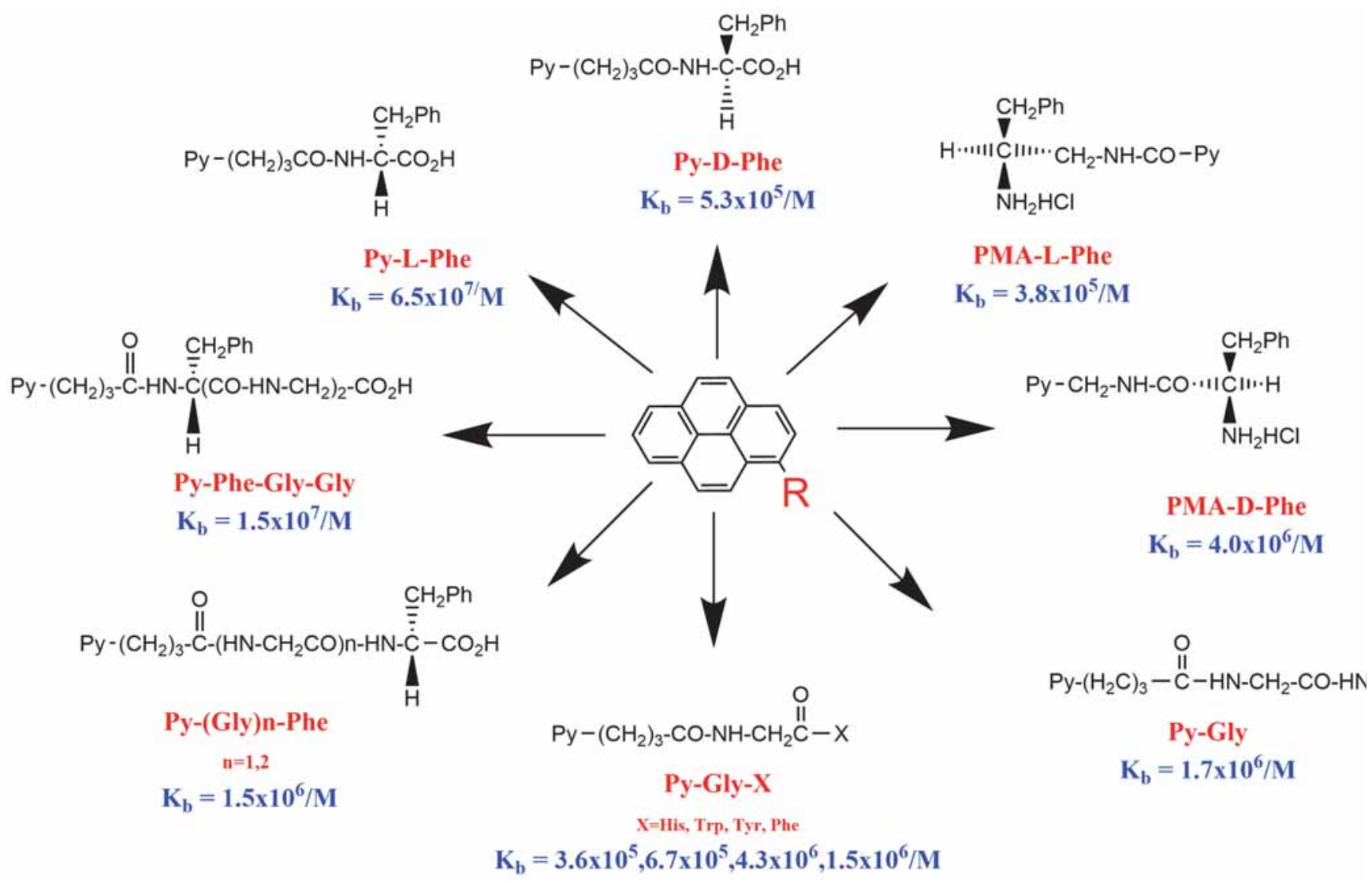

Scheme 3: Structures of several Pyrenyl photoreagents designed, prepared and examined for protein photocleavage. The corresponding binding constants $\left(K_{b}\right)$ of the probes with BSA are shown in blue.

In addition to changing the linker length, we also examined the subtle influence of the polarity of the peptide linker (Scheme 3). Conjugation of the carboxyl terminus of the amino acid to the pyrenyl chromophore, instead, resulted in the corresponding cationic probes, where the polarity of the amide bond has been reversed. This strategy provided a different perspective of the above method where the probe might bind to a site that is near, or at, a negatively charged site on the protein instead of a positively charged site. For example, coupling of the amine group of 4-(1-pyrene) methylamine (PMA) to the carboxyl group of D/L-Phe resulted in the corresponding PMA-D/L-Phe (Scheme 3). In another study, the short peptide or the amino acid linker was replaced with biotin to examine if the 
245 high affinity biotin group would direct the pyrenyl reagent to its corresponding known binding site on 246 avidin.

247 Guided by these interesting strategies, a small library of photoreagents was synthesized, and 248 their interactions with a small set of proteins have been examined here. The pyrenyl chromophore built 249 into these photoreagents also provided a convenient spectroscopic handle to examine the binding 250 interactions of these reagents with the above proteins. These detailed protein binding studies are 251 described next, prior to the delineation of their protein photocleavage properties.

\section{4.1.1 Photophysical Properties \\ 4.1.1.1 Absorbance Titrations}

254

The solvent environment surrounding the pyrenyl chromophore has a strong impact on its 255 electronic levels and this attribute is exploited to evaluate the interactions of the pyrenyl probes with 256 proteins. ${ }^{7}$ When a solution of BSA $(0-2.0 \mu \mathrm{M}, 50 \mathrm{mM}$ Tris- $\mathrm{HCl}$ buffer, $\mathrm{pH}$ 7.0) was titrated into a 257 solution of Py-L-Phe ( $3 \mu \mathrm{M}$, Tris buffer), a small red shift of $4 \mathrm{~nm}$ has been noted. ${ }^{1}$ There was a 258 significant hypochromism at $343 \mathrm{~nm}$, and an isosbestic point at $345 \mathrm{~nm}$ where the absorbance is 259 independent of the protein concentration (Figure 2).

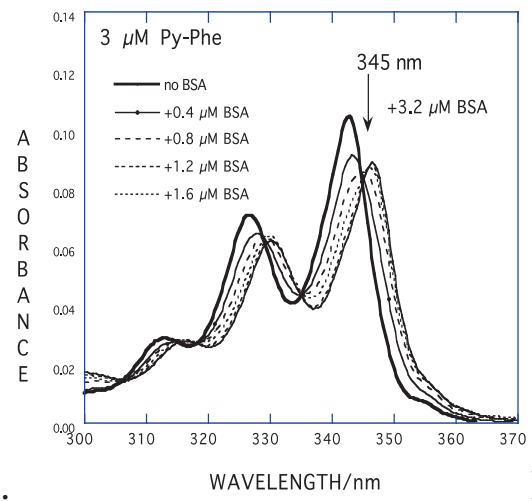

260

A.

B.
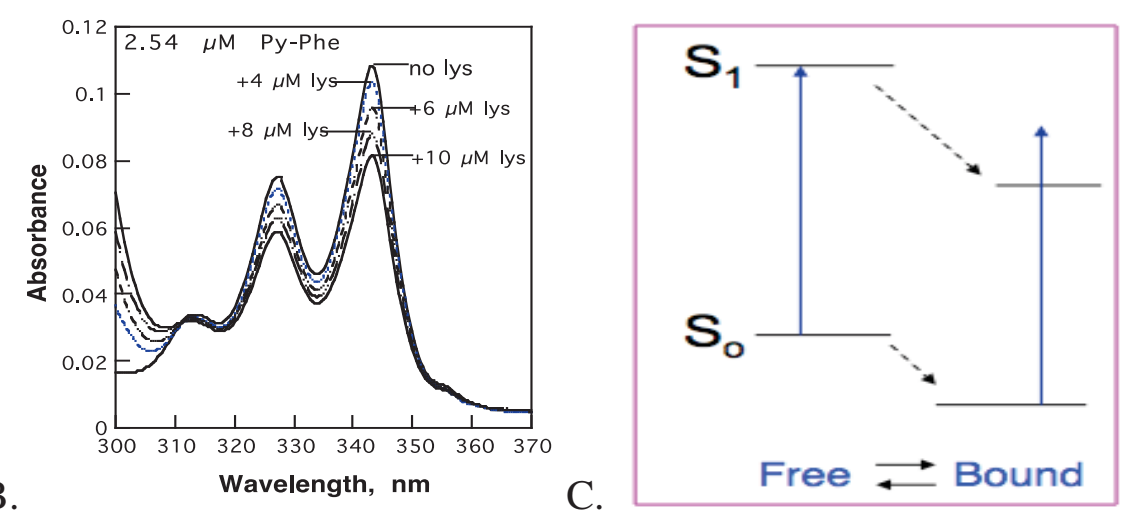

C. 
261 D.

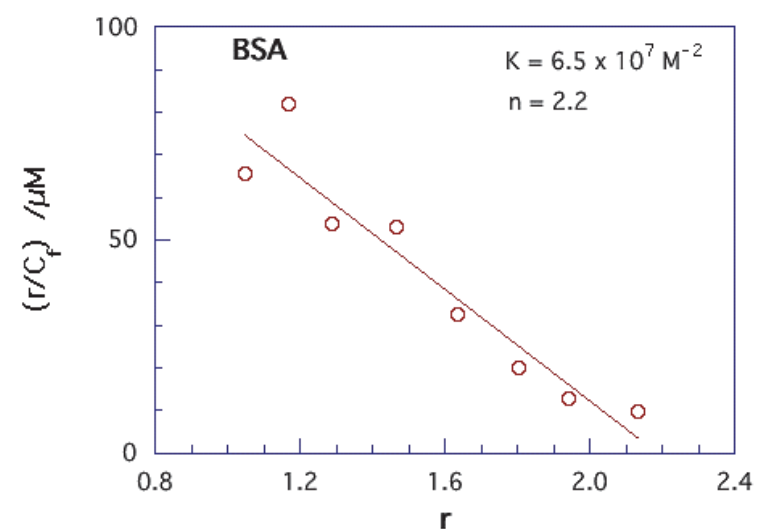

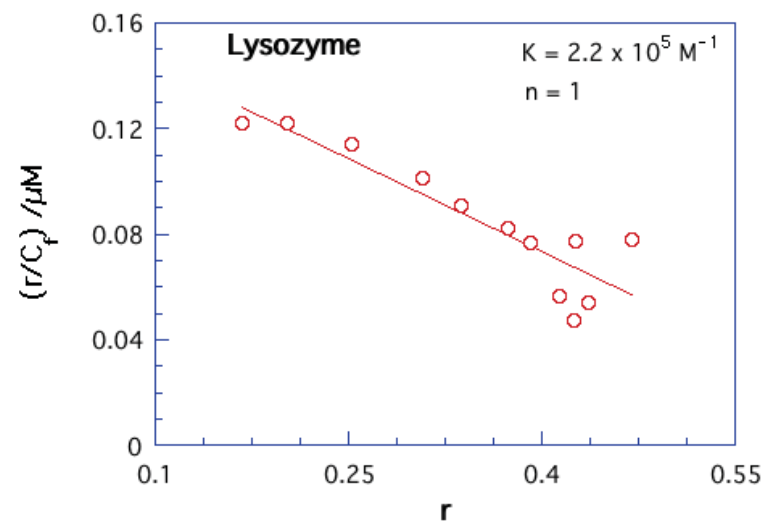

262

263

264

265

266 267

268

269

270

271

272

273

274

275

276

277

278

279

280

281

282

283

284

285
Figure 2. (A) Absorbance spectra of Py-Phe $(3 \mu M)$ with the addition of $B S A(0-3.2 \mu M),(B)$ absorbance spectra of Py-Phe $(2.5 \mu M)$ with the addition of lysozyme $(0-10 \mu M),(C)$ energy level diagram showing the influence of the protein environment on the electronic states, (D) Scatchard plot of Py-Phe with BSA, and (E) Scatchard plot of Py-Phe with lysozyme. Reproduced with permission from Angewandte Chemie, ${ }^{31}$ the Journal of American Chemical Society, ${ }^{32}$ and PNAS. ${ }^{33}$

Because the ground state binds spontaneously to the protein, its free energy is lowered by an amount equivalent to the binding free energy (Figure 2C). As shown by the small red shift in the absorption spectra shows that the energy gap between the excited and the ground state is decreased. One can infer that the excited state has a lower energy in the protein-bound state than in the solvent. Because the gap between the two states is reduced, as indicated by the red shift in the absorption spectra, one concludes that the excited state of the probe binds even better than the corresponding ground state.

The absorption spectral changes of the pyrenyl probes on binding to BSA are summarized in Table 1. All pyrenyl probes that featured a negatively charged end group consistently showed a red shift but there has been no specific trend with the nature of the amino acids in the linker. In general, most of the negatively charged pyrenyl probes seem to interact with a hydrophobic site on BSA in a similar manner, where there has been a bathochromic shift followed by hypochromism. On the other hand, positively charged pyrenyl probes (PMA-D-Phe and PMA-L-Phe) were obtained by the conjugation of 1(1-pyrene)-methyl amine with the carboxyl group of phenylalanine or by conjugation of 4(1-pyrenyl)butyric acid to the carboxyl group of phenylalanine (Phe-Py). These indicated bathochromic shifts but no change in extinction coefficients upon binding to BSA. ${ }^{34}$ Thus, the terminal group of the linker played a very important role in anchoring the protein at distinct locations but the basis for any preference has not been understood. 
287 Table 1. Spectral properties of each analog with BSA and lysozyme. Absorption/emission maximum 288 wavelength is in nm, hyperchromicity/ hypochromicity in percent are given. N/A indicates that the 289 value is unknown.

\begin{tabular}{|l|l|l|l|l|}
\hline Molecule & $\begin{array}{l}\text { Absorption/ } \\
\text { Emission Max } \\
\text { (with BSA) }\end{array}$ & $\begin{array}{l}\text { Hyperchromism/ } \\
\text { Hypochromism } \\
\text { (with BSA) }\end{array}$ & $\begin{array}{l}\text { Absorption/ } \\
\text { Emission Max } \\
\text { (with Lysozyme) }\end{array}$ & $\begin{array}{l}\text { Hyperchromism/ } \\
\text { Hypochromism (with } \\
\text { Lysozyme) }\end{array}$ \\
\hline Py-L-Phe & $343 / 378$ & Hypochromic, 17\% & $347 / 378$ & Hypochromic, 26\% \\
\hline Py-D-Phe & $343 / 378$ & Hyperchromic & $344 / 378$ & Hypochromic, 14\% \\
\hline PMA-L-Phe & $342 / 377$ & N/A & $344 / 378$ & N/A \\
\hline PMA-D-Phe & $342 / 377$ & No Clear change & $345 / 378$ & Hypochromic \\
\hline Phe-Py & $344 / 377$ & N/A & N/A & N/A \\
\hline Py-Gly & $345 / 377$ & Hypochromic & $345 / 377$ & Hypochromic \\
\hline Py-Gly-His & $343 / 378$ & Hypochromic, 3\% & $344 /$ N/A & N/A \\
\hline Py-Gly-Trp & $343 / 378$ & Hyperchromic, 33\% & $346 /$ N/A & N/A \\
\hline Py-Gly-Tyr & $343 / 378$ & Hypochromic, 10\% & $345 /$ N/A & N/A \\
\hline Py-Gly-Phe & $345 / 377$ & Hypochromic, 10\% & $345 / 377$ & N/A \\
\hline Py-Gly-Gly-Phe & $345 / 377$ & Hypochromic & $345 / 377$ & Hypochromic \\
\hline Py-Phe-Gly-Gly & $345 / 377$ & Hypochromic & $345 / 377$ & Hypochromic \\
\hline
\end{tabular}

In order to examine whether the nature of the protein affects the changes in absorption, the 292 interaction of the pyrenyl probes with lysozyme has been examined. ${ }^{3}$ Titration of lysozyme $(0-10 \mu \mathrm{M})$ 293 into a solution of Py-L-Phe (0-50 $\mu \mathrm{M}$, Tris buffer) was shown in Figure 2B. In contrast to BSA 294 (hypochromism, 17\% at $343 \mathrm{~nm}$ ), no red shift occurred in the absorption spectra of Py-L-Phe in the 295 presence of lysozyme, although considerable hypochromism (26\% at $343 \mathrm{~nm}$ ) was observed. ${ }^{35}$ When 296 Py-D-Phe was bound to BSA, hyperchromism (14\% at $343 \mathrm{~nm}$ ) was observed, and there has been 297 considerable influence of the chiral center on the bound probe properties. Titrations of pyrene 298 derivatives of increasing linker lengths indicated no spectral shifts, but hyperchromicity has been 
noted. Derivatives in which the linker was systematically changed showed no shift in the spectra when bound to lysozyme but they exhibited intense hypochromism (Table 1).

Binding of the cationic derivatives (PMA-L-Phe/PMA-D-Phe) to lysozyme also showed only minor changes in their absorbance spectra. The small hypochromicity indicated that the pyrenyl chromophore resides at a hydrophilic site on the protein, probably exposed considerably to the solvent. ${ }^{2}$ Furthermore, the similarities between the spectral properties of PMA-L-Phe and PMA-D-Phe suggested that both the molecules might reside within the same site on lysozyme.

\subsubsection{Binding studies}

307

308

309

310

311

312

313

314

315

316

317

318

319

320

321

322

The absorption titration data are useful to determine the intrinsic binding constants of the probes by using a single occupancy, non-interacting, independent, binding site model using Scatchard equation (Equation 1): ${ }^{36}$

$$
(\mathrm{r} / \mathrm{C}=\mathrm{K}(\mathrm{n}-\mathrm{r}))
$$

Here, $\mathrm{r}$ is the moles of ligand bound per mole of protein, $\mathrm{n}$ is the number of binding sites per protein, and $\mathrm{C}$ is the concentration of the free ligand. Linear fits to the data were obtained in all cases examined here, with two typical plots shown in Figure 2D, E. The corresponding $\mathrm{K}_{\mathrm{b}}$ and $\mathrm{n}$ values extracted from the best fits of the data are shown in Table 2.

Table. 2. Binding constants $\left(\mathrm{K}_{\mathrm{b}}\right)$ for some pyrenyl probes with BSA.

\begin{tabular}{|l|l|l|l|l|l|}
\hline Py-L-Phe & Py-D-Phe & PMA-D-Phe & PMA-L-Phe & Phe-Py & Py-Gly \\
\hline $6.5 \times 10^{7} / \mathrm{M}$ & $5.3 \times 10^{5} / \mathrm{M}$ & $4.0 \times 10^{6} / \mathrm{M}$ & $3.8 \times 10^{5} / \mathrm{M}$ & $2.3 \times 10^{5} / \mathrm{M}$ & $1.7 \times 10^{6} / \mathrm{M}$ \\
\hline Py-Gly-His & Py-Gly-Trp & Py-Gly-Tyr & Py-Gly-Phe & Py-Gly-Gly-Phe & Py-Phe-Gly-Gly \\
\hline $3.6 \times 10^{5} / \mathrm{M}$ & $6.7 \times 10^{5} / \mathrm{M}$ & $4.3 \times 10^{6} / \mathrm{M}$ & $1.5 \times 10^{6} / \mathrm{M}$ & $1.5 \times 10^{6} / \mathrm{M}$ & $1.5 \times 10^{7} / \mathrm{M}$ \\
\hline
\end{tabular}

Some interesting comparisons can made: most ligands had a single binding site with a single occupancy and binding was non-cooperative in all cases examined. Comparisons of the $\mathrm{K}_{\mathrm{b}}$ values of these closely related photoreagents provided important insight into the contributions of specific groups of the ligand toward the binding free energy. For example, the $\mathrm{K}_{\mathrm{b}}$ value of Py-L-Phe for BSA was two orders of magnitude greater than that of Py-D-Phe, which indicates the strong influence of the chiral center of phenylalanine on the binding interaction. This was surprising, because binding was thought to 
be dominated by the large hydrophobic pyrenyl group and not by the smaller Phe. These are the first examples of the highest chiral discrimination noted for man-made compounds with any protein.

Binding of PMA-L-Phe and PMA-D-Phe isomers with BSA indicated chiral selectivity that is 10-fold weaker than that of Py-L-Phe and Py-D-Phe. This decrease may be due to the reversed charge 328 and reversed direction of the peptide linker of PMA-D-Phe and PMA-L-Phe and subsequent binding to a completely different site on BSA. Phe-Py was obtained by conjugating L-Phe with 4(3-pyrene)butylamine and had the amide bond reversed, and positively charged isomer of Py-Phe. In solutions containing the probe and lysozyme, the selectivity is significantly increased as compared to the selectivity noted for Py-Phe and PMA-D-Phe is favored over PMA-L-Phe. This switch further supports that the chiral center plays an important role in binding site recognition in the protein matrix. ${ }^{2}$

Best fits of the single-site binding model to the binding isotherms indicated that there were two different binding sites for Py-L-Phe on BSA, while there was only one site observed for lysozyme. ${ }^{2}$ The binding capability if each molecule, however, is also affected by the linker length, charge, or hydrophobic element. Scheme 3 as well as Table 2 illustrate that shortening the linker from a 5-carbon chain of Py-Phe to 1-carbon chain of PMA-Phe leads to decreased binding. This decrease was possibly due to insufficient separation of the hydrophobic and hydrophilic groups of the probe across the protein/water boundary. One possibility may be that the hydrophobic pyrene group is substantially exposed to the solvent to the protein surface when the chain is shorter, rather than being buried in the hydrophobic interior of the protein.

Binding affinities to BSA were $1.7 \times 10^{6} \mathrm{M}^{-1}$ for Py-Gly, $1.5 \times 10^{6} \mathrm{M}^{-1}$ for Py-Gly-Phe and $1.5 \times 10^{6} \mathrm{M}^{-1}$ for Py-Gly-Gly-Phe. Extension of the hydrophobic segment in the linker from the pyrene chromophore by the addition of Phe, thus contributes to the affinity. This trend, however, was not followed with the Py-Phe or PMA-Phe chiral isomers (Table 2). Py-(Gly) $)_{n}-P h e(n=1$ and 2$)$ affinity for BSA decreased 40-fold when compared to that of Py-L-Phe but only 4-fold less for Py-Phe-Gly-Gly. The addition of 1 or 2 glycine residues in Py-(Gly $)_{n}$-Phe, gave the same binding affinity as Py-Gly, which is interesting because the additional Phe group did not enhance the affinity significantly. Adding glycine residues to the end of Py-Phe only decreases the binding affinity by 4 -fold. ${ }^{7}$

Affinities of Py-Gly-X (X=His, Trp, Tyr, Phe) are inversely proportional to the hydrophilicity of the side chain, and the affinities dropped from $4.3 \times 10^{6} \mathrm{M}^{-1}$ to $3.6 \times 10^{5} \mathrm{M}^{-1}$ as the $\mathrm{X}$ changed. Where 
352 His $<\operatorname{Trp}<$ Phe $<$ Tyr. $^{37}$ The binding is decreased when a larger hydrophilic element is introduced into 353 the side chain (Tyr, Trp, His) instead of hydrophobic residue, Phe. ${ }^{37}$ For example, $\mathrm{K}_{\mathrm{b}}$ of Py-Gly-His

354 (the most hydrophilic) is an order of magnitude smaller $\left(3.6 \times 10^{5}\right)$ than Py-Gly-Phe $\left(1.5 \times 10^{6}\right) .{ }^{37}$

355

356

357

358

359

360

361

362

363

364

365

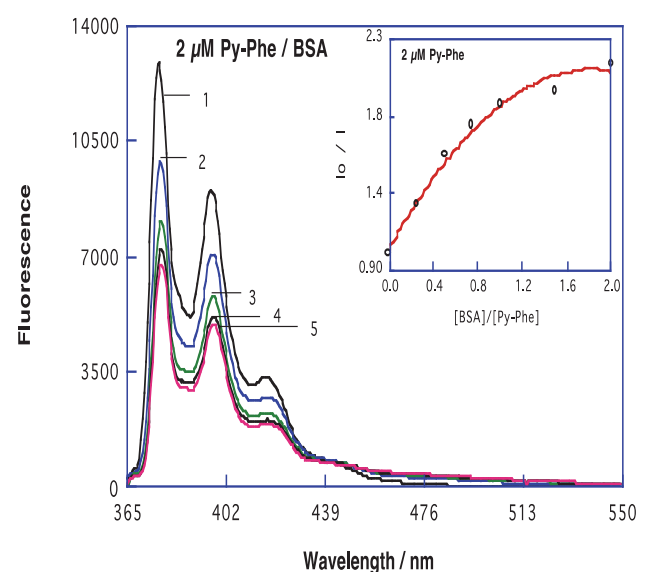

366

A.

369

370

371

\subsubsection{Fluorescence Titrations} Society $^{32}$ and PNAS. ${ }^{38}$

The decrease in the energy gap between the ground and first excited state of Py-Phe, noted from the absorption spectra discussed above, suggested a corresponding red shift in the fluorescence spectrum of the pyrenyl probe. Excimer formation, a process where a complex between the ground and the excited states of the same molecule is formed, ${ }^{37}$ could be examined through the long-lived excited state of the pyrenyl chromophore. ${ }^{29}$ If the bound probe is isolated from the other probe molecules bound to the same protein or different protein molecules during the excited state lifetime, the formation of the excimer is unlikely. On the other hand, if the probe is rapidly exchanging between the bound and free states, then excimer formation is more likely. Also, if the occupancy at the binding site is 2 or more, then excimer formation is more likely than if the occupancy is 1 . Thus, fluorescence studies provided an important avenue to examine binding of the photoreagents to the proteins.

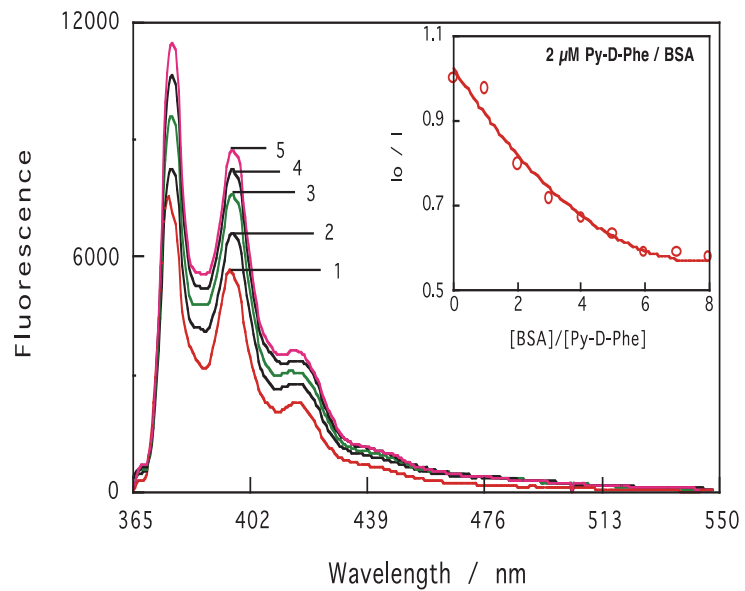

B.

Figure 3. Fluorescence titrations of (A) Py-L-Phe $(0-2 \mu \mathrm{M})$ and (B) Py-D-Phe $(0-2 \mu M)$ with BSA (0-8 $\mu \mathrm{M}$ ) in $50 \mathrm{mM}$ Tris-HCl Buffer ( $\mathrm{pH}$ 7.0), upon excitation at $345 \mathrm{~nm}$. Insets show normalized intensity (I II) vs BSA concentration. Reproduced with permission from the Journal of American Chemical 

buffer, indicated a decrease in fluorescence intensity with increased BSA protein concentration (Figure 3). ${ }^{2}$ In contrast, the fluorescence of PMA-L-Phe, PMA-D-Phe, and Phe-Py bound to BSA was enhanced upon binding, which further supported the absorption titration data and suggested considerably different microenvironments for these two different probes in BSA. ${ }^{2}$ Py-Gly-Tyr's 377 fluorescence was enhanced on binding to BSA, but, Py-Gly-His's fluorescence was quenched which suggested binding of these probes to different sites on the same protein and the terminal residue had a significant effect. ${ }^{37}$ Furthermore, Furthermore, Table 4 shows that fluorescence is significantly lost 380 when the placement of the recognition element is changed, that is, directly attaching it to the 381 chromophore versus including a long linker.

In contrast to BSA, binding of Py-L-Phe $(2 \mu \mathrm{M})$ to lysozyme $(0-10 \mu \mathrm{M}, 50 \mathrm{mM}$ Tris- $\mathrm{HCl}$ buffer, $\mathrm{pH}$ 7.0) induced weak quenching of the pyrenyl chromophore at $345 \mathrm{~nm}$, inferring that the binding site lies on the surface of the protein. No peak shifts were observed PMA-L-Phe and PMA-DPhe was bound to lysozyme. ${ }^{2}$ The fluorescence of probes with different linkers indicated no substantial 386 changes, which is indicative that the binding site is located on the surface of lysozyme, fairly exposed to the solvent in all cases studied here. Titrations of the Py-(Gly) $)_{\mathrm{n}}$-Phe analogues of increasing chain lengths also indicated weak quenching of their fluorescence with no shifts in their spectral maxima. ${ }^{7}$

In all of the above cases, we did not find excimer emission in the presence of lysozyme, which 390 suggested that the pyrenyl chromophore is buried in the protein in its monomeric form (single occupancy). ${ }^{4}$ However, with BSA, excimer formation was observed in some cases (Py-L-Phe, Phe-Py and Py-Gly-Gly-Phe), which indicated that the pyrenyl chromophore is buried in the protein in its dimeric form or two of the probes could find each other within the excited state lifetime. ${ }^{7,35,37}$

\subsubsection{Circular Dichroism Studies}

Many of the pyrenyl probes investigated here had intrinsic CD bands in the region of the pyrene absorption spectra from one or more asymmetric centers in their side chains (Figure 4, Table 3). 399 Close interaction of the probes pyrenyl chromophore with the chiral environment of the protein was expected to have a strong influence on the intrinsic CDs of the pyrenyl probes. The isomers Py-L-Phe and Py-D-Phe, for example, exhibited CD spectra that were near-mirror images of each other in the absence of the protein (Data not shown). ${ }^{35}$ Upon binding to BSA $(55 \mu \mathrm{M})$ the CD peaks of both 
401 isomers were inverted with peak positions at $327 \mathrm{~nm}$ and $345 \mathrm{~nm}$ for the L isomer and at $330 \mathrm{~nm}$ and $402347 \mathrm{~nm}$ for the D isomer (Figure 4A). ${ }^{4}$

403 The CD intensity when bound to BSA decreased for PMA-L-Phe and increased for PMA-D-Phe 404 (Figure 4C, D). ${ }^{2}$ Py-Gly had no asymmetric center and thus had no intrinsic CD bands but when bound 405 to BSA it indicated induced CD bands at 314, 334 and, $350 \mathrm{~nm}$. Therefore, the induced CD confirms 406 the asymmetric environment around the pyrene chromophore in the bound state even when it is not 407 intrinsic to the probe.

408 Although the absorbance and fluorescence spectra of Py-(Gly $)_{n}$-Phe bound to BSA are similar, 409 their CD spectra varied substantially, providing a unique "fingerprint" for each probe. The variation 410 comes from changes to their microenvironments at the binding site such as, the orientation of the 411 pyrenyl chromophore with respect to its own asymmetric center, or the protein asymmetric 412 environment around it. ${ }^{7}$ When the linker length is increased, as in the case of Py-Phe-Gly-Gly, the CD 413 ellipticities changed only marginally (Figure 4E). Lastly, the CD spectra reported here are unique to a 414 given protein and the probe. With respect to lysozyme, only minor changes were observed (Figure 4B). 

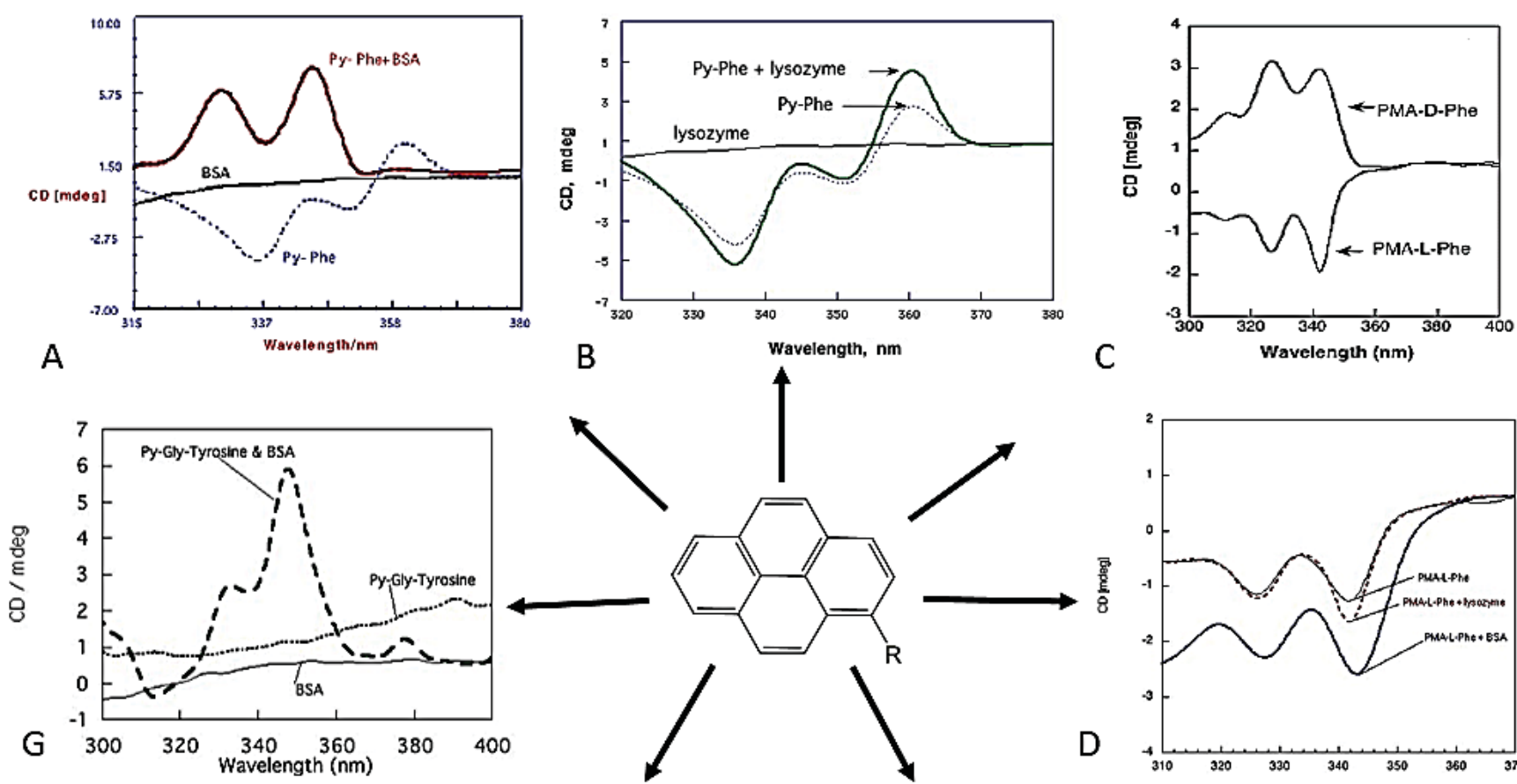

\section{C}
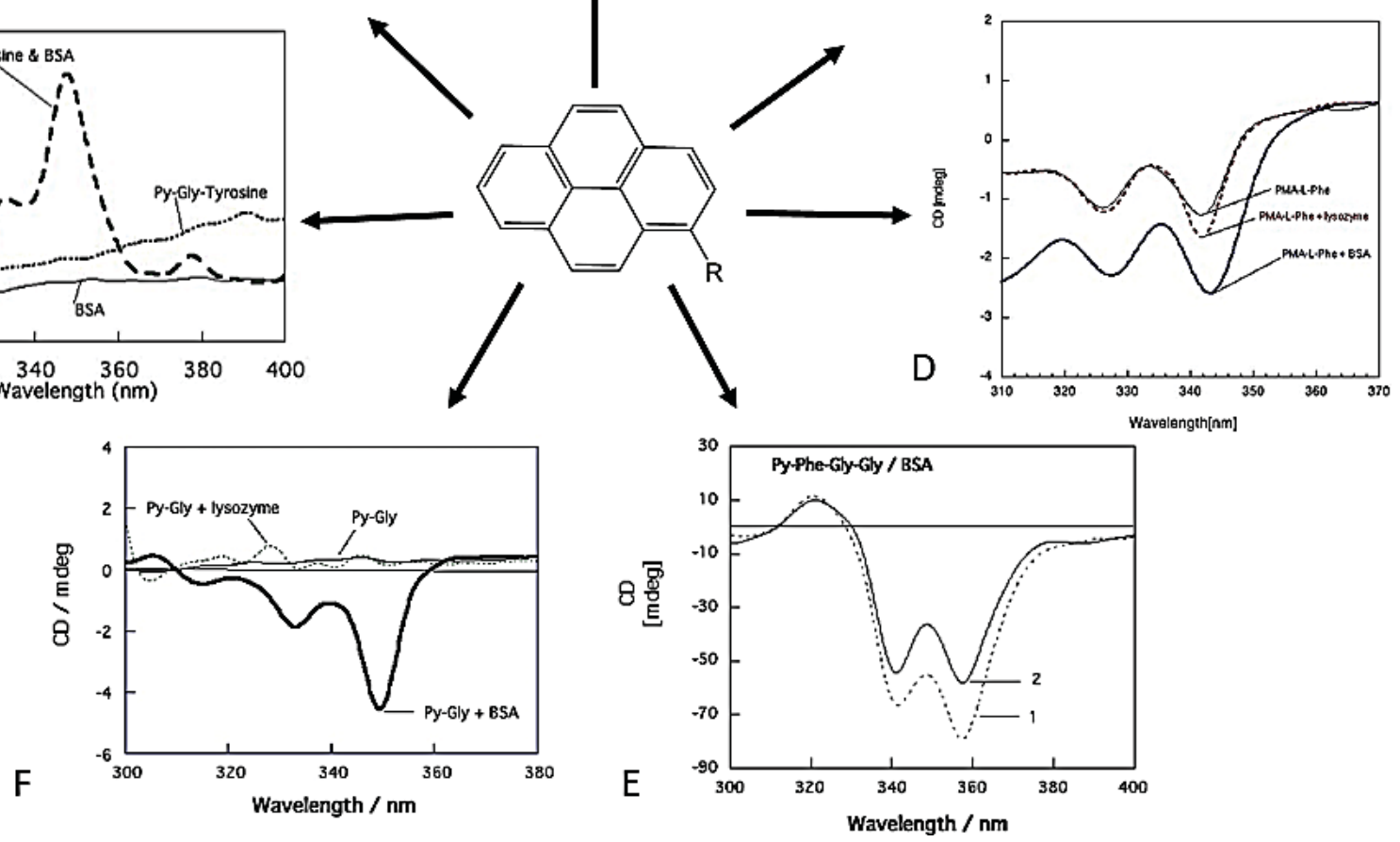

Figure 4. CD spectra of the Py-Phe family of probes bound to the target proteins. In all cases concentrations were $50 \mu M$ Py-Phe, $50 \mu M$ protein in Tris buffer (50 mM, pH 7.2), unless otherwise stated. (A) Py-Phe bound to BSA, (B) Py-L-Phe bound to lysozyme, (C) free PMA-D-Phe and PMA-LPhe (30 $\mu M)$ in Tris Buffer, (C) PMA-D-Phe and PMA-L-Phe (30 $\mu M)$ bound to BSA or lysozyme, (D) free PMA-L-Phe (30 $\mu \mathrm{M}$, solid line) and bound BSA or lysozyme (bold and dashed lines, respectively), (E) Py-Phe-Gly-Gly in the absence (dotted line) and presence of BSA (solid line), (F) Py-Gly bound to BSA or lysozyme, and $(G)$ free Py-Gly-Tyrosine (dotted line), Py-Gly-Tyrosine bound to BSA (dashed line) and free BSA (solid line).

One overarching observation could be made from the small set of CD spectra shown in Figure 
427 the same CD spectrum a given probe. This outcome is mostly likely due to the unique chiral 428 environment the probe experiences while residing in the protein matrix. These spectra could serve as 429 'fingerprints' for a given protein or for a given probe. But this inference needs to be tested further for 430 any practical applications of CD spectra for the identification of the probes or the proteins.

432 Table 3. Circular dichroism bands (nm) of Py-Phe and its derivatives

\begin{tabular}{|l|l|l|}
\hline Molecule & Negative CD Peaks (nm) & Positive CD Peaks (nm) \\
\hline Py-D-Phe & 330 and 347 (bound to BSA) & -- \\
\hline Py-L-Phe & 336,351, and 360 nm (Free Probe) & 327 and 345 (bound to BSA) \\
\hline PMA-D-Phe & -- & 330 and 346 (bound to BSA) \\
\hline PMA-L-Phe & 328 and 344 (bound to BSA) & -- \\
\hline Py-Gly & 328 and 342 (bound to lysozyme) 354 (bound to Lysozyme) & \\
\hline Py-Phe-Gly-Gly & $\begin{array}{l}341 \text { and } 357 \text { (Free probe) } \\
342 \text { and } 358 \text { (bound to BSA) }\end{array}$ & -- \\
\hline
\end{tabular}

433

\subsubsection{Fluorescence quenching Studies}

Solvent accessibility of the protein-bound photoreagent is crucial in our strategy of achieving 436 photocleavage reaction. That is, the pyrenyl chomophore is to sensitize the photodecomposition of 437 CoHA to generate reactive amine radical which could abstract a hydrogen atom from the peptide 438 backbone and initiate the cleavage chemistry. Therefore, quenching of fluorescence from the protein439 bound pyrenyl probes by CoHA were assessed, systematically. The corresponding Stern-Volmer 440 quenching constants $\left(K_{\mathrm{SV}}\right)$ have been determined for the photoreagents by fluorescence quenching 441 studies and compared (Table 4). For example, the quenching constants were calculated using the 
442 fluorescence intensities in the presence and absence of CoHA using the Stern-Volmer equation 443 (equation 2),

$$
\mathrm{Io} / \mathrm{I}=1+\mathrm{KsV}[\mathrm{Q}]
$$

445 Where [Q] is the quencher concentration, and $K_{\mathrm{sv}}$ is the Stern-Volmer constant, I is the fluorescence 446 intensity in the presence of specific concentration of $\mathrm{CoHA}$ and $\mathrm{I}_{0}$ is the corresponding value in the 447 absence of CoHA. ${ }^{39}$ Linear relationships were observed in almost all cases when plotting $\mathrm{I}_{0} / \mathrm{I}$ vs 448 CoHA concentration, using the Stern-Volmer equation. $K_{\mathrm{sv}}$ decreased when the photoreagent was 449 bound to the protein, depending on the degree of accessibility of the probe to the aqueous media, 450 excited state lifetime as well as the diffusion coefficient of the quencher.

Table 4. Fluorescence quenching by CoHA for probes bound to BSA or lysozyme, as indicated $\left(M^{-1}\right)$.

\begin{tabular}{|l|l|l|l|l|l|l|l|l|}
\hline Probe & Py-L-Phe & $\begin{array}{l}\text { Py-D- } \\
\text { Phe }\end{array}$ & $\begin{array}{l}\text { PMA-L- } \\
\text { Phe }\end{array}$ & $\begin{array}{l}\text { PMA-D- } \\
\text { Phe }\end{array}$ & Py-Gly & Py-Gly-Phe & $\begin{array}{l}\text { Py-Gly- } \\
\text { Gly-Phe }\end{array}$ & $\begin{array}{l}\text { Py-Phe- } \\
\text { Gly-Gly }\end{array}$ \\
\hline $\begin{array}{l}K_{\text {sv }} / \mathrm{M} \\
(\text { free } \\
\text { Probe })\end{array}$ & $1.9 \times 10^{3}$ & $1.9 \times 10^{3}$ & $1.28 \times 10^{3}$ & $2.31 \times 10^{3}$ & $1.3 \times 10^{3}$ & $1.3 \times 10^{3}$ & $1.9 \times 10^{3}$ & $1.3 \times 10^{3}$ \\
\hline $\begin{array}{l}K_{\text {sv }} / \mathrm{M}(2 \\
\mu \mathrm{M} \text { BSA })\end{array}$ & $0.25 \times 10^{3}$ & $\begin{array}{l}\text { Intensity } \\
\text { enhanced }\end{array}$ & $\begin{array}{l}\text { Intensity } \\
\text { enhanced }\end{array}$ & $0.15 \times 10^{3}$ & $0.31 \times 10^{3}$ & $0.38 \times 10^{3}$ & $<10$ & $<10$ \\
\hline $\begin{array}{l}K_{\text {sv }} / \mathrm{M}(2 \\
\mu \mathrm{M} \\
\text { lysozyme }\end{array}$ & $1.4 \times 10^{3}$ & $0.53 \times 10^{3}$ & $0.79 \times 10^{3}$ & $0.72 \times 10^{3}$ & $1.2 \times 10^{3}$ & $1.0 \times 10^{3}$ & $0.36 \times 10^{3}$ & $0.82 \times 10^{3}$ \\
\hline
\end{tabular}

452

The quenching data collected in Table 4 clearly shows that Py-L-Phe and Py-D-Phe, for 454 example, are quenched with equal efficiency in the absence of the protein. On binding to the protein, 455 however, the efficiency changes dramatically; Py-L-Phe when bound to BSA or lysozyme quenched 456 the fluorescence by $13 \%$ or $74 \%$ respectively. The decrease in the $K_{\mathrm{sv}}$ which occurs when the probe binds to the protein, points to the extensive decrease in accessibility of the probe to the quencher, when the quencher is present in the solvent. ${ }^{3}$ We assume that CoHA does not bind to the protein, and this assumption may not be valid in some specific cases when the quencher also binds to the protein. Large decrease in the quenching constant implies extensive protection of the probe from the quencher by the 
461 protein, and it is less likely that the excited probe would sensitize the photodecomposition of CoHA. 462 The photocleavage yield, therefore, expected to be low.
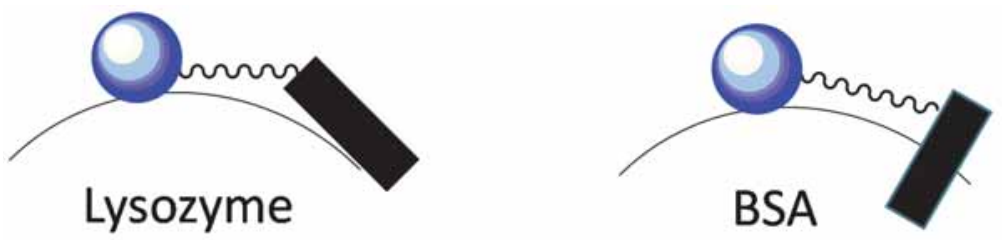

463

464 Scheme 4: Differences in the solvent exposure of photoreagents when bound to lysozyme vs BSA. The 465 black rectangle represents the chromophore, the blue ball represents the polar head group, and the 466 black squiggle represents the linker.

467

468 With Py-L-Phe $(2 \mu \mathrm{M})$ bound to BSA $(2 \mu \mathrm{M})$, the emission is weakly quenched $\left(K_{\mathrm{sv}}=0.25 \times 10^{3}\right.$, 469 unlike its counterpart in which the emission is enhanced (Table 4). The quenching constants for 470 cationic probes such as PMA-Phe observed the opposite trend; with the L isomer having enhanced 471 fluorescence and the $\mathrm{D}$ isomer being quenched $\left(K_{\mathrm{sv}}=0.15 \times 10^{3}\right)$. For probes in which the linker length 472 was changed, the efficiency changes as the distance between the recognition element and the 473 chromophore are adjusted. The fluorescence quenching constants for the BSA-bound probe decreased 474 with increasing linker length. ${ }^{7}$ In the presence of lysozyme $(2 \mu \mathrm{M})$, Py-L-Phe $(2 \mu \mathrm{M})$ is quenched 475 more efficiently than the D isomer. PMA-D-Phe and PMA-L-Phe showed little difference in 476 quenching constants when bound to lysozyme $\left(K_{\mathrm{sv}}=0.72 \times 10^{3}\right.$ and $0.79 \times 10^{3}$ respectively $){ }^{2}$ The $K_{\mathrm{sv}}$ 477 values for analogues containing different lengths of linker were significantly larger than the ones 478 observed in the presence of BSA. $K_{\mathrm{sv}}$ values (Table 4) indicate that the probe binds near surface of 479 lysozyme with good exposure to the solvent. This continues to show the ease of accessibility of the 480 probe to solvent-bound $\mathrm{CoHA}$ at least when the probe was bound to lysozyme. Based on these studies, 481 we proposed that probes bound to BSA are, in general, well-protected by the protein while the probes 482 bound to lysozyme are much more accessible to the solvent-bound CoHA (Scheme 4). ${ }^{3,35}$ These 483 deductions are important and explain the greater yields of protein cleavage products with lysozyme 484 when compared to those with BSA.

\subsubsection{Chiral discrimination and fluorescence lifetime studies}


An unexpected outcome of our studies has been achieving high chiral discrimination of photoreagent binding to the proteins, for a man-made molecule. Py-L-Phe, for example, indicated a 488 binding affinity for BSA which is nearly 100 times greater than the corresponding D-isomer, Py-D-Phe (Table 2). ${ }^{40}$ The chiral discrimination is also evident from the absorbance and fluorescence spectral titrations, discussed earlier. The absorbance spectrum for Py-L-Phe, for example, showed hypochromism when bound to BSA, while Py-D-Phe showed hyperchromism. ${ }^{4,6,35}$ Fluorescence spectra also showed a similar contrast in that Py-L-Phe intensity decreased on binding to BSA while that of Py-D-Phe has been enhanced. Furthermore, time resolved fluorescence data showed that when bound to BSA, the lifetimes of these two probes are different (Figure 5). Their lifetimes in solution were identical (105 ns, air saturated solutions) and hence, the differences arose upon their binding to the protein. Furthermore, the fluorescence lifetimes increased on binding to the protein. Figure 5 shows two distinct components of $\sim 70$ and $153 \mathrm{~ns}$ for the $\mathrm{L}$ isomer and $\sim 70$ and $168 \mathrm{~ns}$ for the D isomer. ${ }^{40}$ The two isomers did not differ in terms of their photoproduct yields, described later. Chiral discrimination of Py-Phe isomers noted with lysozyme, however, has been substantially greater than that noted with BSA. ${ }^{40}$

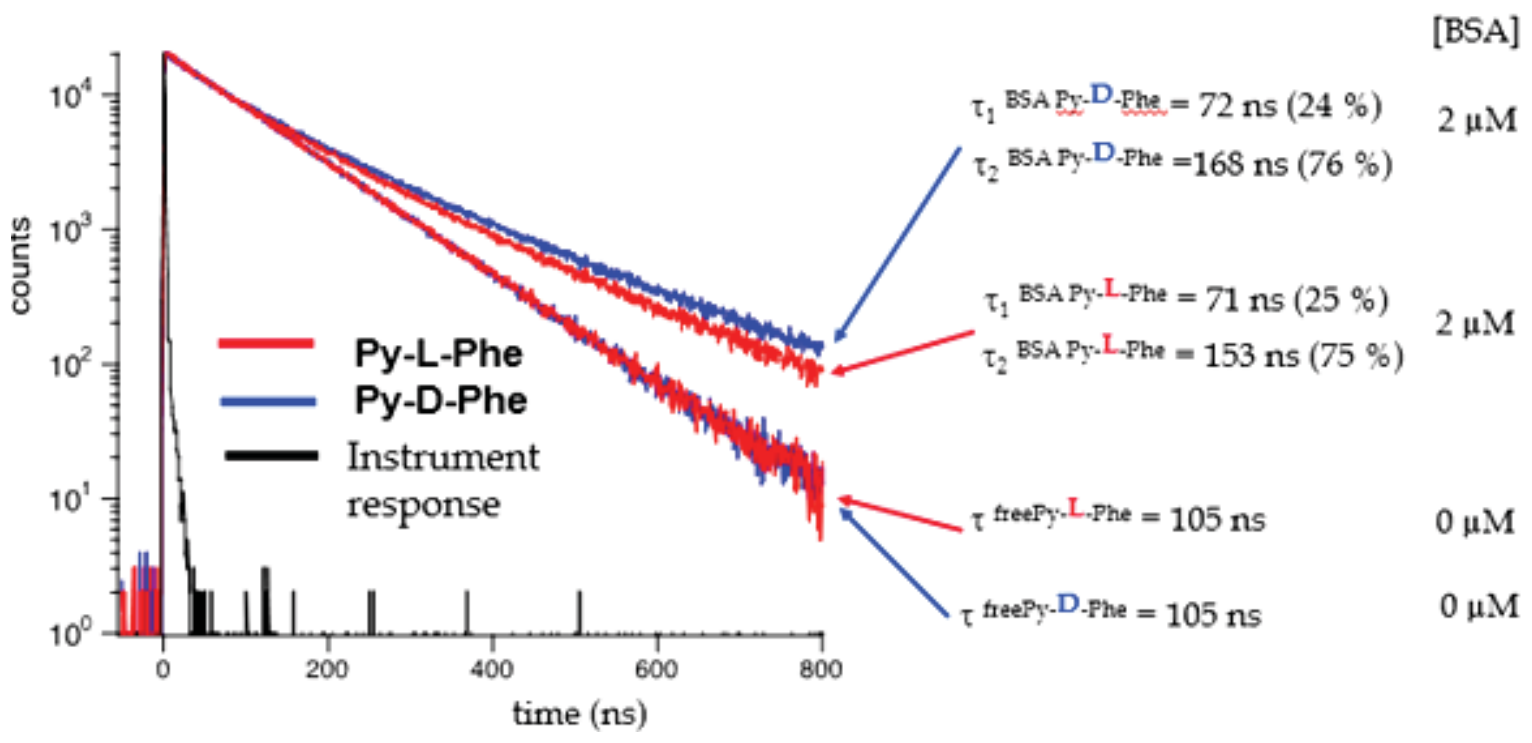

Figure 5. Fluorescence decay curves of Py-L-Phe and Py-D-Phe $(2 \mu \mathrm{M})$ in the absence and presence of 503 BSA (2 $\mu M)$. Py-L-Phe and Py-D-Phe bound to BSA showed biexponential decays. Reproduced with 504 permission from PNAS. ${ }^{38}$ 


\subsubsection{Photochemical Studies}

Our major goal for these studies was to evaluate the photochemical cleavage of proteins by these photoreagents and quantify the details of the photoreaction. Knowing the identity of the photoreagent binding site on the proteins is an important detail to fully understand the above experimental data and the photocleavage mechanism. These details were assessed directly from photochemical studies by irradiating a mixture of the photoreagent, the quencher and, the protein at appropriate wavelengths for substantial duration. The pyrenyl chromophore by itself is not photoactive and Py-Phe does not cleave proteins when irradiated with near UV light $(\sim 340 \mathrm{~nm})$. The long lived excited state of the probe and its facile access to CoHA suggested that sensitized photochemical reaction could be used to induce protein photocleavage. Since CoHA has been known to undergo photodecomposition giving rise to $\mathrm{NH}_{2}$ radicals, ${ }^{4}$ we imagined that photogeneration of these reactive species at the probe binding site could initiate peptide bond cleavage. The photocleavage of the protein backbone is then expected to form smaller fragments than the parent, which could be separated by standard protein gel electrophoresis (SDS/PAGE) studies. The newly formed amino terminus of the peptide was amenable to amino acid sequencing, therefore, giving the exact details of the cleavage patterns of the photoreactions. This unexpected feature is useful in biochemical applications of these photoreagents.

\subsubsection{SDS/PAGE Studies}

Solutions containing CoHA $(1 \mathrm{mM})$, BSA $(15 \mu \mathrm{M})$ and Py-L-Phe $(15 \mu \mathrm{M})(50 \mathrm{mM}$ Tris-HCl buffer, $\mathrm{pH} 7.0$, total volume $200 \mathrm{uL}$ ) were irradiated at $343 \mathrm{~nm}$ for increasing periods of time, using a $150 \mathrm{~W}$ xenon lamp with a cutoff filter (WG-345) for removing of stray UV light. Py-Phe/BSA had an absorbance maximum at this wavelength and the photoreaction progress has been monitored by sodium dodecyl sulfate polyacrylamide gel electrophoresis (SDS/PAGE) studies. The products are separated by applying electric field and their migration through the gel depends on their size. ${ }^{41}$ The reaction mixtures were loaded onto the gel, electrophoresed, and after developing the gel bands by appropriate stain, there appeared sharp protein bands. In most cases we examined, these gels indicated the formation of just two product bands of lower molecular weight than the parent protein (Figure 6A, lanes 4-7), in addition to the band of the unreacted protein. Control lanes with no CoHA (Figure 6A, Lane 9) or no Py-Phe (Figure 6A, Lane 10) or no light (Figure 6, Lane 3) did not indicate any product. Thus, the photoreaction required light, CoHA, the photoreagent and the protein and resulted in a pair of products due to a single cut in the peptide backbone. The sum of the molecular weights of the two 
537 product bands equaled to that of BSA, further establishing that there has been a single cleavage site. If 538 the photocleavage was random, then these bands would have been a smear and the sum of the product 539 molecular weights would differ from that of BSA ${ }^{1}$ The photochemical product yield was calculated 540 through quantification of the gel using NIHimage software (v 1.6), in which the total intensity of the 541 fragment bands were divided by the total intensity in the entire lane.

542
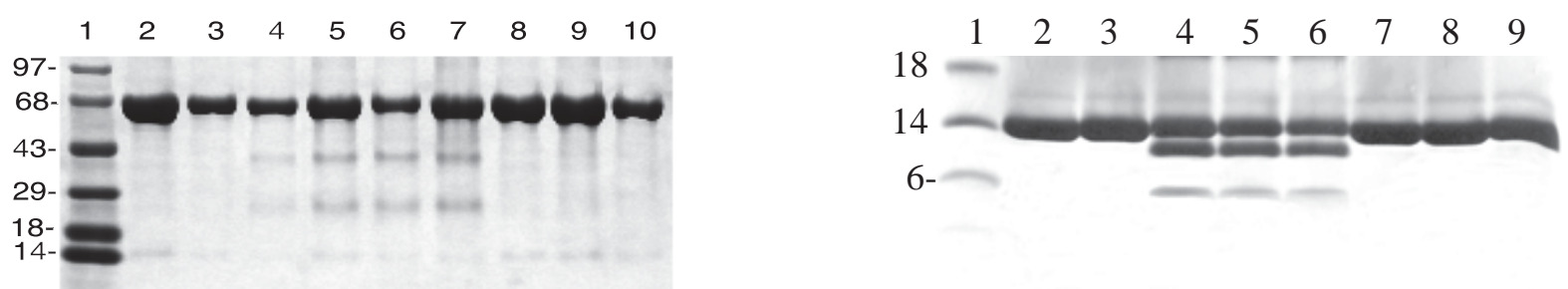

A.

B.

543 Figure 6. A. SDS/PAGE gel of BSA photoreaction. Lane 1: Molecular weight markers in kDa, Lane 2: 544 BSA (15 $\mu \mathrm{M})$, Lanes 3-7: BSA+Py-L-Phe+CoHA, all irradiated for 0 (dark control), 10, 20,30 and 60 545 minutes at 344 nm, Lane 8: BSA, Lane 9 BSA+Py-L-Phe, Lane 10: BSA + CoHA, Lanes 8-10 546 irradiated for 30 minutes. B. SDS/PAGE gel of lysozyme photoreaction. Lane 1: Molecular weight 547 markers in kDa, Lane 2: Lysozyme (15 $\mu \mathrm{M})$, Lanes 3-6: Lysozyme+Py-D-Phe+CoHA irradiated for 548 0,5,10, and 20 minutes at $344 \mathrm{~nm}$, Lane 7: Lysozyme, Lane 8: Lysozyme+ Py-D-Phe, Lane 9: 549 Lysozyme+CoHA, Lanes 7-9 irradiated for 20 minutes. Reproduced with permission from Angewandte 550 Chemie $^{31}$ and $P N A S^{38}$.

551

552

553

554

555

556

557

558

559

560

To test if the photoreaction is just unique to BSA or more generally applicable, we also examined the photoreaction of lysozyme with Py-D-Phe. Since this probe binds to lysozyme and its excited state has been accessible to CoHA, shown in quenching studies, this was a reasonable expectation. Irradiation of Py-D-Ph/lysozyme mixture (50 mM Tris- $\mathrm{HCl}$ buffer, $\mathrm{pH} 7.0)$ at $334 \mathrm{~nm}$ resulted in two distinct products as noted in the SDS/PAGE (Figure 6B). These are of lower molecular weight than that of lysozyme. Lanes containing dark control (lane 3) showed no reaction as the lanes that contained just protein and Py-D-Phe or protein and CoHA but irradiated with light (lanes 8 and 9). Irradiation time is optimal at 20 minutes, after that photocleavage reached a plateau. Furthermore, the sum of the molecular weights of the two bands equaled that of the parent protein, indicating that a single cut has been made (Figure 6B, lanes 4-6). ${ }^{35}$ Not only does Py-D-Phe photocleave lysozyme at a single site, but it also had among the highest photoproduct yields (21\%, Table 5). This increased yield 563 is consistent with higher Stern-Volmer quenching constants noted with lysozyme when compared to 
564 those of BSA. From these gels of BSA and Lysozyme, we conclude that the reaction requires all three 565 components, light, CoHA, and Py-Phe to proceed.

566 Table 5. The photocleavage yields for BSA and lysozyme with the Py-Phe and its derivatives.

\begin{tabular}{|l|l|l|}
\hline Probe/Protein & BSA & Lysozyme \\
\hline Py-L-Phe & $25 \%$ & $35 \%$ \\
\hline Py-D-Phe & $25 \%$ & $21 \%$ \\
\hline Phe-Py & $<5 \%$ & $42 \%$ \\
\hline PMA-L-Phe & $<5 \%$ & $57 \%$ \\
\hline PMA-D-Phe & $<5 \%$ & $52 \%$ \\
\hline Py-Gly-Phe & $<5 \%$ & $21 \%$ \\
\hline Py-Gly-His & $5 \%$ & $15 \%$ \\
\hline Py-Gly-Tyr & $<5 \%$ & $7 \%$ \\
\hline Py-Gly-Trp & $<5 \%$ & $<5 \%$ \\
\hline Py-Phe-Gly-Gly & $5 \%$ & $22 \%$ \\
\hline Py-(Gly)n-Phe (n=1,2) & $5 \%$ & $17 \%$ \\
\hline
\end{tabular}

567

Along these lines, we examined the photoreactivities of Py-D-Phe, PMA-L-Phe and PMA-DPhe, with both BSA and lysozyme and all of which produced a single pair of photoproducts in good to moderate yields (Table 5). The latter indicated much weaker product yields but there has been no chiral discrimination in terms of the product yields. However, the product yields for the photocleavage reaction differ significantly (Table 5). Photoproduct yields of BSA with Py-Phe-Gly-Gly (yields <5\%, irradiated at $344 \mathrm{~nm}$ for 60 minutes) are lower than those observed with lysozyme (22\%), because the probe bound to lysozyme is exposed to the solvent and its emission has been more efficiently quenched by CoHA. In contrast, the probes bound to BSA are buried in a deep hydrophobic cavity, making them less accessible to CoHA, as indicated by the fluorescence quenching data. Even in the case of BSA, where the probes are less accessible, there has been substantial photocleavage resulting in a single pair of product bands. Yields for lysozyme/PMA-Phe photoreactions (Figure 7A) were quite high (57\%) even when compared to that of lysozyme/Py-L-Phe $(35 \%)^{2}$ (Table 5), which are consistent with the fluorescence quenching studies discussed earlier. Photoreaction yields were also calculated for the cleavage of lysozyme by Phe-Py (Figure 7B), a molecule similar to PMA-Phe in that the charge is 
582 reversed (Table 5). Interestingly enough, Phe-Py cleaved lysozyme in a very similar fashion to PMA583 Phe (Figure 7 A, B)

584

585

with Py-Gly-Phe, Py-Gly-Tyr, and Py-Gly-His (Table 6). ${ }^{6}$ Py-Phe and Py-Gly-His showed 586 considerable yields, while the Tyr and Trp analogs did produce any photoproducts. Flash photolysis 587 studies showed that the Tyr and His residues quench the initially produced radical intermediate in the 588 589 mechanism (discussed later), thus quenching the reaction at the initial stages. The photoproduct yields of Py-Gly-X derivatives (where X was one or more amino acids shown in Table 6) with lysozyme 590 were higher than the corresponding values noted with BSA (Table 6). Increased photoproduct yields are consistent with increased access of the chromophore to CoHA.

592

A.

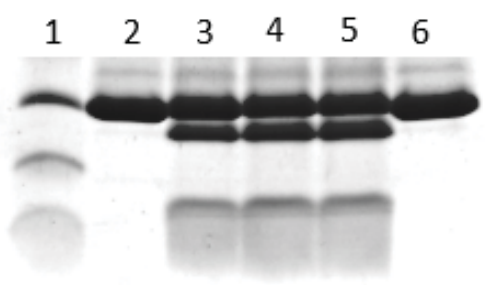

B.

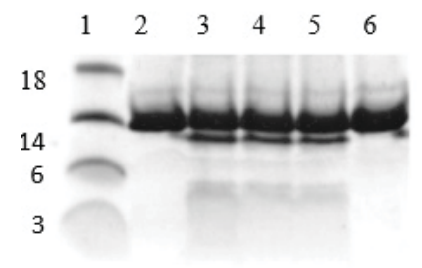

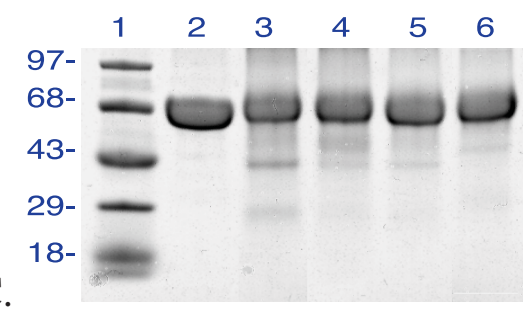

C.

593 Figure 7. (A) SDS/PAGE of lysozyme photocleavage with PMA-Phe upon excitation at $342 \mathrm{~nm}$. Lane

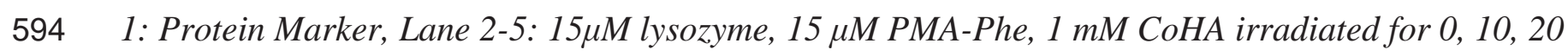
595 minutes, Lane 6: $15 \mu$ M lysozyme and $15 \mu M$ PMA-Phe irradiated for 30 minutes. (B) SDS/PAGE of 596 lysozmye cleavage with Phe-Py, upon excitation at $344 \mathrm{~nm}$. Lane 1: Protein Marker, Lane 2-5:5 $\mathrm{MM}$

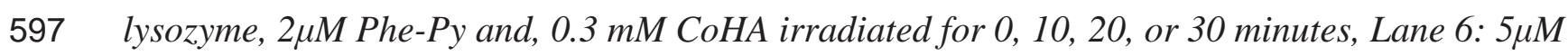
598 lysozyme and $2 \mu M$ Phe-Py irradiated for 30 minutes (C) SDS/PAGE gel of BSA cleavage with Py599 (Gly)n-Phe analogues upon excitation at 344 nm. Lane 1: protein marker, lane 2: BSA, Py-L-Phe, 600 CoHA (Dark control), Lane 3: BSA, Py-L-Phe, CoHA Lane 4: BSA, Py-Gly-Phe, CoHA, Lane 5: BSA 601 Py-Gly-Gly-Phe, CoHA, Lane 6: BSA, Py-Phe-Gly-Gly, CoHA. Samples in lanes 3-6 were irradiated 602 for 60 minutes. Reproduced with permission from the Journal of American Chemical Society. ${ }^{32}$ 603 Next, we examined the influence of the linker length on the photocleavage yield because a 605 606 607 greater distance between the hydrophobic and hydrophilic groups in the probe should bury the pyrenyl group further into the protein interior. This should bury the pyrenyl chromophore further into the protein matrix and cleave the protein further down the peptide chain. This simple strategy could allow 
608

609

610

611

612

613

614

615

616

617

618

619

620

621

622

623

624

625

626

627

628

629

630

631

632

633

634

us to tune the location of the cleavage site. Py- $(\mathrm{Gly})_{n}-\mathrm{Phe}$ analogues $(\mathrm{n}=0,1,2)$ are used to test this strategy. The yields of the photoproducts with BSA as the target protein decreased for $\mathrm{n}=0,1$ and 2 , (Figure 7C, lanes 4-6) when compared to that of Py-L-Phe. ${ }^{7}$ These observations were, again, consistent with the quenching data presented earlier.

\subsubsection{Quantum yield measurements}

The quantum yield of the photocleavage reaction of Py-L-Phe with lysozyme was 0.26, which is quite respectable considering that it is a photoreaction with a macromolecule. ${ }^{3,6}$ The quantum yield of photocleavage of BSA by Py-L-Phe was 0.0021, which is much less efficient than that of lysozyme for reasons discussed above. ${ }^{3,6}$

\subsubsection{Peptide Sequencing Studies}

Sequencing the newly produced product peptides would reveal the exact location of the cleavage site on the protein, and identifying the photocleavage site is an important step in understanding the mechanism as well as for applications in protein photo-sequencing studies. ${ }^{2,3,5,7,35}$ This was done by standard biochemical methods of amino acid sequencing. ${ }^{42}$ Western blotting of the photofragments separated on SDS-polyacrylamide gel were transferred to PVDF membrane by applying a current of $60 \mathrm{~mA}$ for $1.5 \mathrm{~h}$ by the semi-dry system (BIORAD) in CAPS (3(cyclohexylamino)-1-propanesulfonic acid) buffer, $\mathrm{pH}$ 10.5. The transferred protein bands were stained with Coomassie Brilliant Blue, bands were cut, and submitted for N-terminal sequencing. The newly formed $\mathrm{N}$-terminus of the product band was sequenceable, in all the cases we have examined so far, and this is a good outcome for the identification of the photocleavage sites. In some cases, the newly formed C-terminus was blocked from sequencing but both the original $\mathrm{N}$-terminus and Cterminus were sequenceable. These termini were not damaged during the photoreaction and the sequencing data confirmed the identities of the product bands.

Table 6. Photocleavage sites of pyrenyl probes with BSA and lysozyme.

\begin{tabular}{|l|l|l|}
\hline Probe/Protein & BSA Cleavage Site & Lysozyme Cleavage Site \\
\hline Py-L-Phe & Leu346-Arg347 & Trp108-Val109 \\
\hline Py-D-Phe & Leu346-Arg347 & Trp108-Val109 \\
\hline
\end{tabular}




\begin{tabular}{|l|l|l|}
\hline PMA-L-Phe & Not Sequenced & Trp108-Val109 and a minor site \\
\hline PMA-D-Phe & Not Sequenced & Trp108-Val109 and a minor site \\
\hline Py-Gly-Phe & Leu346-Arg347 & Trp108-Val109 \\
\hline Py-Gly-His & Leu346-Arg347 & Trp108-Val109 \\
\hline Py-Gly-Tyr & Leu346-Arg347 & Trp108-Val109 \\
\hline Py-Gly-Trp & Leu346-Arg347 & Trp108-Val109 \\
\hline Py-Phe-Gly-Gly $(\mathrm{n}=1,2)$ & $\begin{array}{l}\text { major sites, not } \\
\text { sequenced }\end{array}$ & Trp108-Val109 and Ala110-Trp111 \\
\hline
\end{tabular}

635

636

637

638

639

640

641

642

643

644

645

646

647

648

649

650

651

652

653

654

655

656

Amino acid sequencing of photo fragments of the BSA/Py-L-Phe photoreaction indicated that the protein is cleaved at Leu-346 and Arg-347 (Table 6), a site that is buried within the protein. To our surprise, both L and the D isomers cleaved at exactly the same site, despite the differences in their binding properties noted earlier. There were no other detectable products in the sequencing analysis, thus corroborating with the above observation that BSA was cleaved at a single site by both Py-L-Phe and Py-D-Phe. That is, the photocleavage has been site specific, an unexpected success, given the great many possible sites the probe could have bound on the protein or cleaved at any of the numerous amide linkages.

Amino acid sequencing of Py-(Gly $)_{\mathrm{n}}$-Phe and its analogues indicated that that the cleavage site is the same for most of the probes examined here, for a given protein. Only occasionally, there have been minor differences noted. That is, the photocleavage is not amino acid sequence dependent but protein site dependent. The BSA fragments were separated, purified, and sequenced in many cases. Based on SDS-PAGE results of photocleavage reactions with the analogues and BSA (Figure 7), there appears to be a dependence on the probes structure in terms of how efficient the probe is and the location at which it cleaves. For example, Py-Gly-Phe and Py-Gly-Gly-Phe (Figure 7C, lane 4 and 5) showed 3 product bands while Py-Phe-Gly-Gly shows just 2 product bands (Figure 7C, lane 6). ${ }^{7}$ The changes in the photoproducts indicate that the selectivity varies from probe to probe. All probes examined here, cleaved lysozyme between Trp108 and Val109, and in the cases of Py-(Gly) $)_{\mathrm{n}}$ Phe and Py-Phe-Gly-Gly a minor cleavage site was noted at Ala110 and Trp111.

Similarly, N-terminal sequencing of the fragments from Py-L-Phe/lysozyme indicated that the protein was cleaved between Trp108-Val109, a site internal to lysozyme, again there were no other 
657 products in the sequencing analysis. Both $\mathrm{L}$ and $\mathrm{D}$ isomers cleaved at the same site, and both cleaved 658 lysozyme at a single site, site specific (Table 6). ${ }^{37}$

659 The photocleavage site of PMA-Phe on lysozyme was determined to be at Trp108-Val109 for both L 660 and the D isomers but noted another very minor fragment with the D isomer, which could not be 661 identified due to its low yield. ${ }^{2}$ However, this minor product was not observed with the L-isomer or 662 with the Py-Phe isomers discussed above (Table 6).

663

664

665

Amino acid sequencing studies of Py-(Gly)n-Phe analogues indicated that the major cleavage site on lysozyme was Trp108-Val109 as with Py-Phe, but it also indicated a minor site between Ala110 and Trp $111^{35}{ }^{7}$ Increasing the length of the linker resulted in a change of cleavage site, as well as loss of site specificity (Table 6). Thus, the linker length does influence binding affinity to the protein, site of binding and photocleavage properties of the probes.

\subsubsection{Computational Modeling}

Next, we examined the binding of specific photoreagents to the target proteins by computational modeling to gain a better understanding of how the protein fragmentation occurred at 671 the specific sites identified in the sequencing studies. The availability of powerful modern software and high capacity computational clusters made this type of modeling routine in our laboratories, and hence some of these unpublished details are presented here. Computational modeling has been, luckily, in good agreement with the established cleavage sites of the probes described here, thus validating the modeling studies. Modeling studies may be used in future studies, with caution, prior to the photochemical studies, and this strategy could provide an iterative method to refine probe design based on the desired target site.

The modeling studies used the known crystal structures of the proteins such as BSA (PDB file name, 4OR0), obtained from the Protein Data Bank and any ligands present in the protein has been 680 removed. The photoreagent structure was optimized by Gaussian 03 at HF/3-21G level of calculation ${ }^{43}$ and AutoDock 4.2 has been used to calculate the interaction energy between the probe and the protein, after energy minimization. The size of the docking box was set at 120 x 120 x $120 \AA^{3}$ with the spacing of $0.375 \AA$. The center of grid box was located at the center of macromolecule with the coordinate 

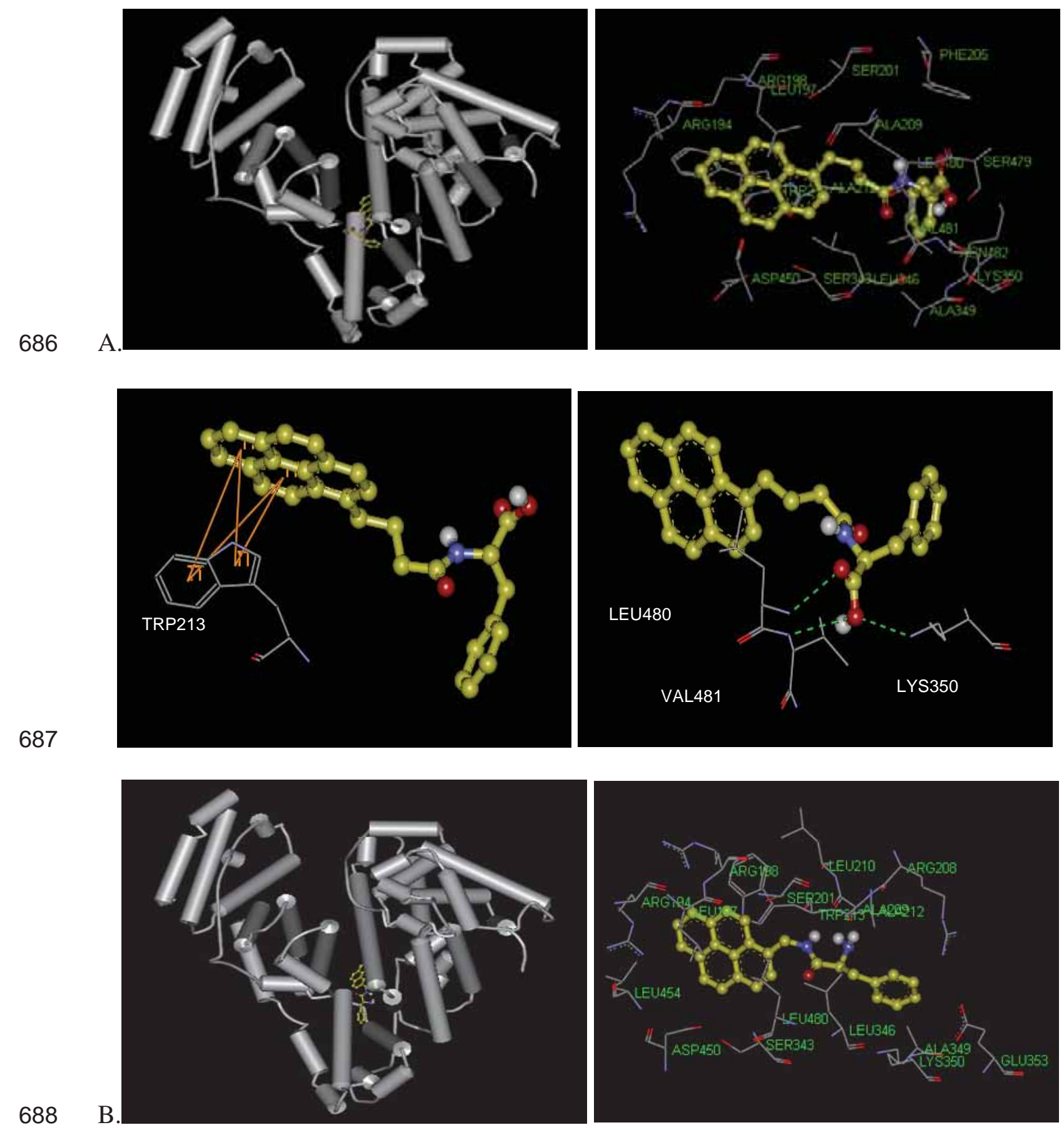

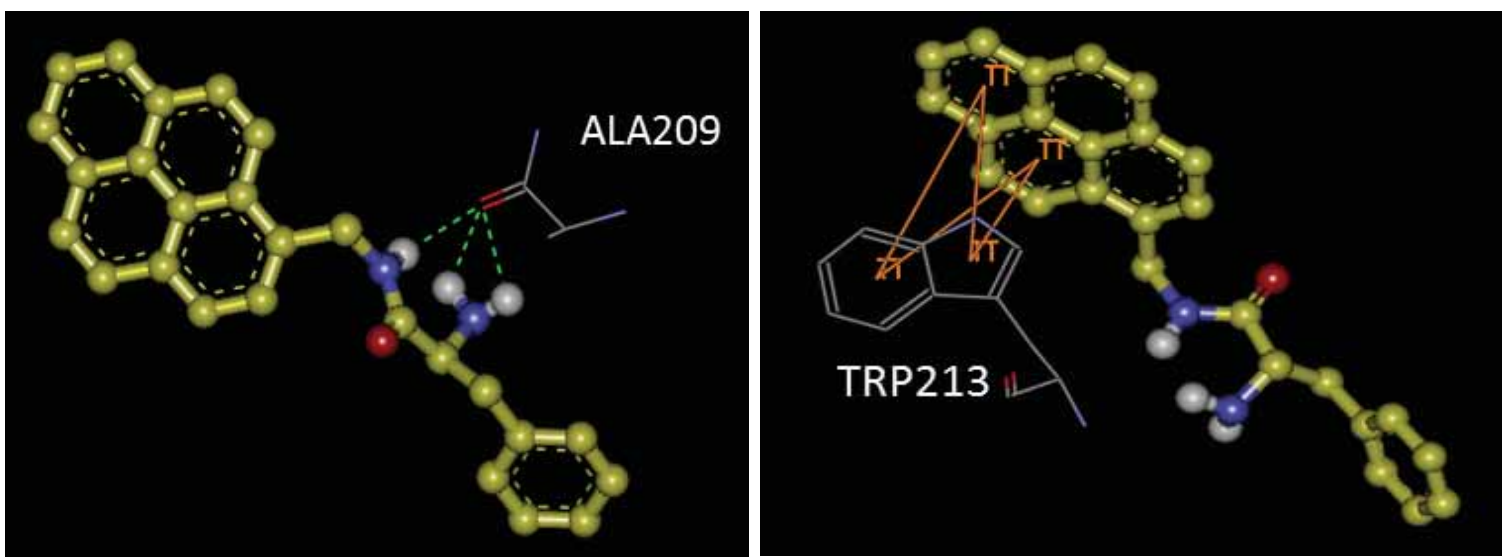

690

Figure 8. Docking study of BSA with Py-L-Phe (A) and PMA-L-Phe (B). Py-L-Phe indicates hydrogen 691 bonding interactions with Lys350, Leu480, Val481 and hydrophobic interaction with Trp213, while 692 PMA-L-Phe indicates hydrogen bonding interactions with Ala209 and hydrophobic interaction with 693 $\operatorname{Trp} 213$.

694

695

The docking results with BSA/Py-L-Phe are shown in Figure 8A, which supported the observed 696 photocleavage site of Leu346-Arg347 in domain II. Modeling showed that this site is located within 697 an alpha helical region, and clearly indicated the strong possibility of stacking interactions between the 698 pyrenyl chromophore of Py-Phe and Trp213. The computed binding free energy of $-13.5 \mathrm{kcal} / \mathrm{mol}$ 699

700 compared well with the binding studies described earlier. Using the equation 3:

$$
\Delta \mathrm{G}=-\mathrm{RT} \ln \mathrm{K}_{\mathrm{b}}
$$

702

Where $\mathrm{R}=1.9872036 \mathrm{calK}^{-1} \mathrm{~mol}^{-1}, \mathrm{~T}=273 \mathrm{~K}$, experimental binding energies were calculated 703 (Table 7). Although lower than the ones determined using computational modeling, but they follow the same trend. Hydrogen bonding interactions between the Py-L-Phe and lys350, leu480, val481 are 704 705 clearly supported, and the cleavage site is in good proximity to the phenyl group of Py-L-Phe (Table 7).

706

707 Table 7: Computational calculations of Distance between Pyrene and the cleavage site $(\AA)$ and the 708 binding free energy $(\mathrm{kcal} / \mathrm{mol})$

\begin{tabular}{|l|l|l|l|l|l|}
\hline & Distance & Distance & BSA Binding & Lysozyme Binding & Binding Free \\
\hline
\end{tabular}




\begin{tabular}{|l|l|l|l|l|l|}
\hline & $\begin{array}{l}\text { between Py to } \\
\text { BSA Cleavage } \\
\text { site }(\AA)\end{array}$ & $\begin{array}{l}\text { between Py to } \\
\text { lysozyme } \\
\text { Cleavage site } \\
(\AA)\end{array}$ & $\begin{array}{l}\text { Free Energy } \\
(\mathrm{k} \quad \mathrm{cal} / \mathrm{mol}) \\
(\text { Calculated })\end{array}$ & $\begin{array}{l}\text { Free Energy } \\
\mathrm{cal} / \mathrm{mol}) \\
(\mathrm{calculated})\end{array}$ & $\begin{array}{l}\text { Energy } \\
(\mathrm{kcal} / \mathrm{mol}) \\
(\text { experimental })\end{array}$ \\
\hline Py-L-Phe & 3.719 & 3.083 & -13.25 & -8.95 & $-9.76(\mathrm{BSA})$ \\
\hline Py-D-Phe & 3.993 & 3.510 & -12.79 & -9.38 & $-7.15(\mathrm{BSA})$ \\
\hline PMA-L-Phe & -- & 3.742 & -11.11 & -11.05 & $-6.97(\mathrm{BSA})$ \\
\hline PMA-D-Phe & -- & 3.282 & -11.27 & -11.09 & $-8.25(\mathrm{BSA})$ \\
\hline
\end{tabular}

710 In a similar manner, we identified the docking site of PMA-L-Phe on BSA (Figure 8B), which 711 binds with a lower affinity $(\Delta \mathrm{G}=-11.11 \mathrm{kcal} / \mathrm{mol})$ than Py-L-Phe. The docked site is in good 712 proximity to the observed cleavage site, but this structure indicated hydrogen bonding with Ala209. 713 The differences of the binding free energies between these two probes, at the same site, could result 714 from the large differences in the conformation of the photoreagents and the distances from the residues 715 that interact with them (Table 7). These differences, however, did not change the photoproduct 716 identity but PMA-Phe isomers had a much lower photocleavage yields than Py-Phe isomers, which 717 suggests that the conformation of the bound photoreagent in the binding pocket is important in 718 determining its reactivity.

\section{4.1.4 Flash Photolysis Studies and the Mechanism}

720 Laser flash photolysis was used to study the mechanism of the photoreaction and examine the 721 intermediates formed subsequent to the photoexicitation. ${ }^{3,35,37}$ Light pulses of $\sim 10 \mathrm{~ns}$ width at $355 \mathrm{~nm}$ 722 were used to excite solutions of $20 \mu \mathrm{M}$ Py-L-Phe, $3 \mathrm{mM}$ CoHA and $30 \mu \mathrm{M}$ BSA or lysozyme (Figure 723 9). 
724

A.

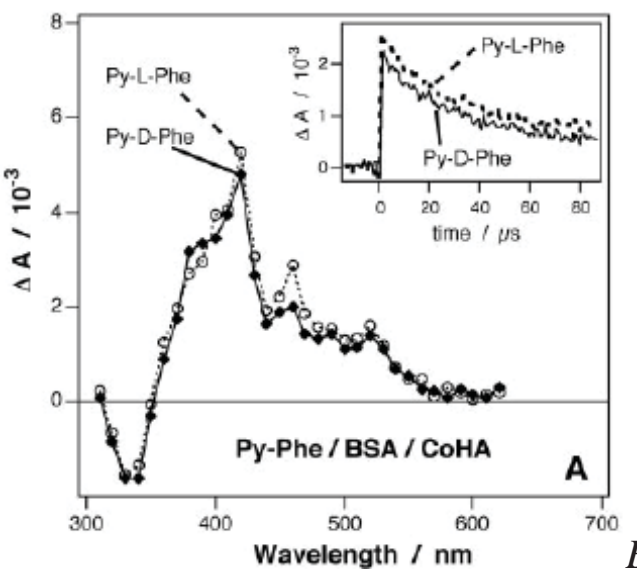

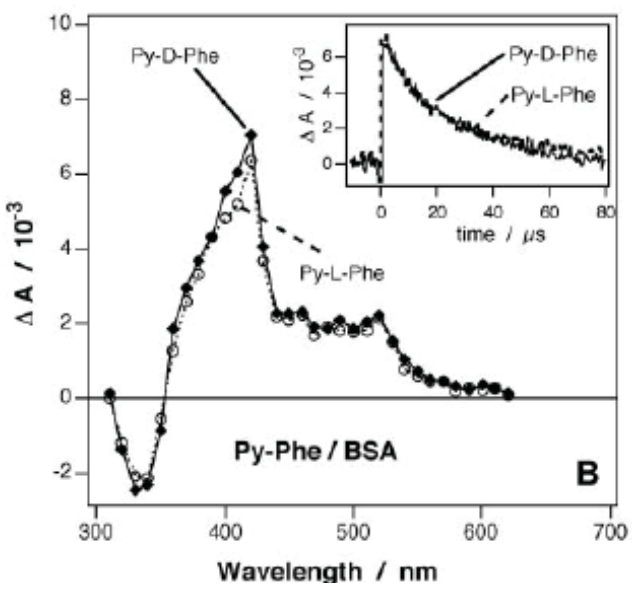

725

726

727

728

729

730

731

732

733

734

735

736

737

738

739

740

741

742

743

744

Light excitation was followed by rapid rise of a transient with absorption maxima at 405, 420, 460, 490, and $510 \mathrm{~nm}$ for BSA, while the corresponding lysozyme/probe samples had bands at 390, 425, 470, and $510 \mathrm{~nm}$. The same time-resolved spectra were noted for either of the Py-D-Phe isomers, and hence, both reactions generated the same reactive intermediates. This transient has been identified, next, in kinetic studies described below.

Kinetic traces recorded at the absorption maxima of the above transient showed that the band corresponding to $460 \mathrm{~nm}$ had a half-life of $50 \mu \mathrm{s}$ (Figure 9A, inset). This intermediate has been identified as the pyrene cation radical, from a number of quenching studies and control experiments. This transient was also formed when Py-Phe excited state was quenched by $3 \mathrm{mM} \mathrm{CoHA}$, in the absence of the protein. ${ }^{3,3737}$ Thus, this intermediate does not originate from the protein or its side chains, but derived from the probe itself. The $460 \mathrm{~nm}$ transient was also not quenched by oxygen to any significant extent, ruling out the possibility that it could be the Py-Phe triplet state. In the absence of CoHA, both Py-L-Phe and Py-D-Phe produced a transient with an absorption maximum at $420 \mathrm{~nm}$ and a lifetime of $18 \mu \mathrm{s}$ (Figure $9 \mathrm{~B}$ ). The transient at $420 \mathrm{~nm}$ was quenched by oxygen at diffusion controlled rates, and has been identified as the pyrene triplet state. The 460 transient was absent under these conditions. 


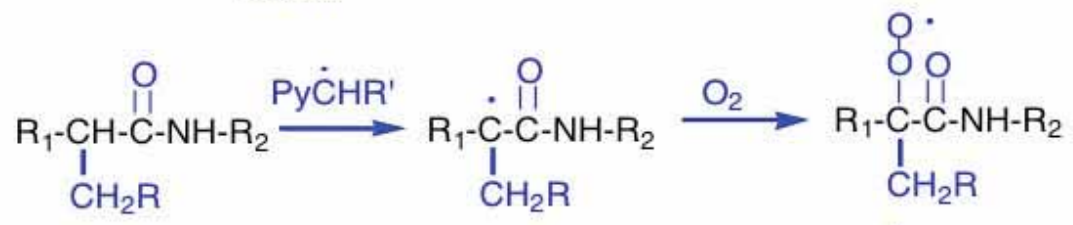

\section{Figure 10: Proposed mechanism for protein photocleavage by Py-Phe and its derivatives.}

748 Thus, our hypothesis of CoHA quenching the probe excited state and producing the corresponding 749 cation radical is supported by the flash photolysis data. The proposed mechanism ${ }^{2,3,7,35}$ (Figure 10) is 750 consistent with the observations that the newly formed N-terminus is sequenceable as well as the 751 cleavage always occurred next to an amino acid bearing beta hydrogens. Many alternative 752 mechanisms could be written for this reaction, but most of these do not account for the presence of free 753 N-terminus of the daughter fragment or justify the need for an accessible $\beta$ hydrogen at the cleavage 754 site. The pyrene cation radical formed from the probe excited state by quenching with CoHA might 755 lose a proton and become the corresponding aryl radical, which could react with oxygen to form

756 hydroperoxyl radical that could eventually lead to peptide backbone cleavage. ${ }^{2,3,7,35}$ Due to the large 757 size and complex structure of the protein, more detailed studies are required to identify further details 758 of the photocleavage mechanism arising from the cation radical.

\subsection{Avidin-based Pyrenyl Probes}

Next, we tested if the pyrene probe could be directed to specific sites on the protein by linking it to biological ligands that are known to bind to a particular target protein, at known sites. Biotin, for 762 example, is known to bind to avidin, a tetrameric glycoprotein with a molecular weight of $15 \mathrm{kDa}$ per one subunit. ${ }^{25}$ The binding constant for this interaction is very high $\left(10^{15} \mathrm{M}^{-1}\right)$, one of the strongest noncovalent protein-ligand interactions known. Therefore, we decided to conjugate the pyrene 
765 chromophore to biotin, and test if the binding is dominated by the hydrophobic pyrene or the high 766 affinity biotin with avidin.

\section{4.2.1 Synthesis and Characterization of Py-Biotin}

$768 \quad$ Coupling of 1(1-pyrene)methylamine hydrochloride with d-biotin by using $N, N^{\prime}$-dicyclohexyl 769 carbodiimide $^{5}$ (Scheme 5) produced d-biotinyl-1(1-pyrene) methylamide (Py-Biotin), with 770 characterization data as follows: ${ }^{1} \mathrm{H}$ NMR (400 MHz; $\mathrm{d}_{6}$-DMSO): 7.8-8.2 (9H), $5.0(1 \mathrm{H}), 4.1(1 \mathrm{H}), 3.8$ $771(1 \mathrm{H}), 3.3(2 \mathrm{H}), 2.5-2.6(2 \mathrm{H}), 2.2(2 \mathrm{H}), 1.1-1.7(6 \mathrm{H})$; MS data: $m / z 456.4\left(\mathrm{M}^{+}\right)$, which are consistent 772 with the assigned structure. ${ }^{5}$ Next, we examined the binding and photoreactions of Py-Biotin with 773 avidin as the corresponding substrate to test if the binding is dominated by the pyrene chromophore or 774 the biotin, which is a poular biological recognition element.

775

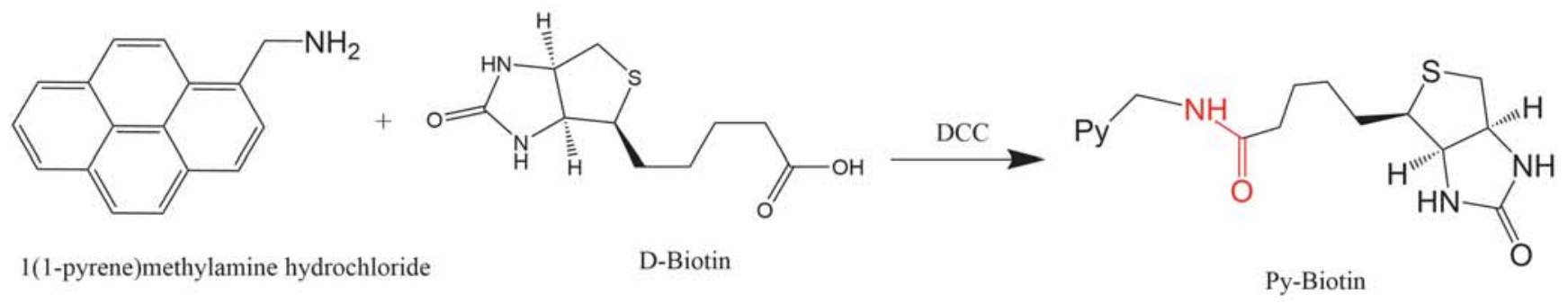

776

Scheme 5.Structure of d-biotinyl-1(1-pyrene)methylamide (Py-Biotin), synthesized by coupling of $d$ 777 biotin to 1(1-pyrene)methylamine hydrochloride (Amide bond highlighted in red).

778

779

\subsubsection{Photophysical studies of Py-Biotin with Avidin}

\subsubsection{Absorbance Titrations:}

781

Pyrenyl chromophore linked to biotin, in the form of Py-Biotin, is expected to be delivered to 782 the specific site on avidin because the binding affinity of biotin for its site on avidin should far exceed 783 the binding affinity of pyrene. This is because biotin is known to have the strongest affinity for any known ligand for a protein. ${ }^{25}$ Addition of avidin solution $(0-1.5 \mu \mathrm{M})$ to a solution of Py-biotin (4.2 $\mu \mathrm{M})$, resulted in a small red shift in the absorbance spectrum and hyperchromism with an absorption maximum at $342 \mathrm{~nm} .^{5}$

\section{7}

\subsubsection{Fluorescence Titrations}


The fluorescence of Py-Biotin is enhanced by the addition of avidin $(0-10 \mu \mathrm{M})$ to Py-biotin solution $(2 \mu \mathrm{M}$, excitation at $342 \mathrm{~nm}$, data not shown), indicating that protein/Py-biotin complex is 790 formed. ${ }^{5}$ No exicmer emission or peak shifts were observed in the spectra. The enhanced emission 791 could be because the binding site is buried within the protein and protected from the solvent. The 792 decreased accessibility of Py-Biotin to the solvent was probed by using CoHA as a quencher and the 793 $K_{\text {sv }}$ is dramatically reduced from $1400 \mathrm{M}^{-1}$ (free probe) to $170 \mathrm{M}^{-1}$ (bound probe, Figure $11 \mathrm{~B}$ ) ${ }^{5}$. This 794 large decrease in access to CoHA could negatively impact photocleavage reaction because this 795 quenching is essential for the photoreaction.

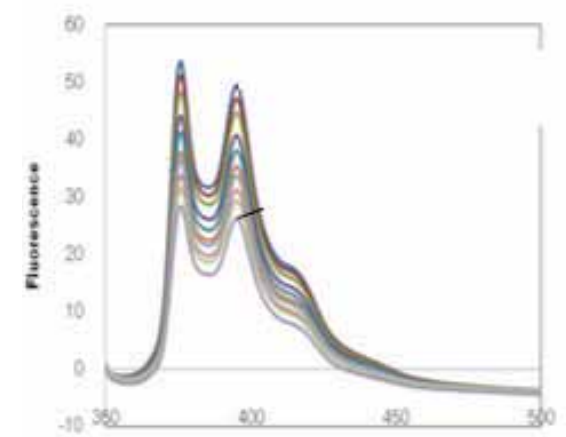

A.

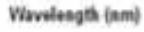

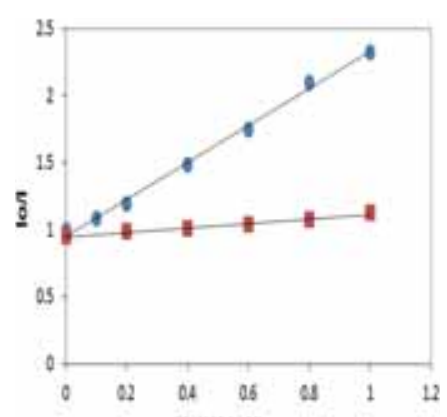

B.

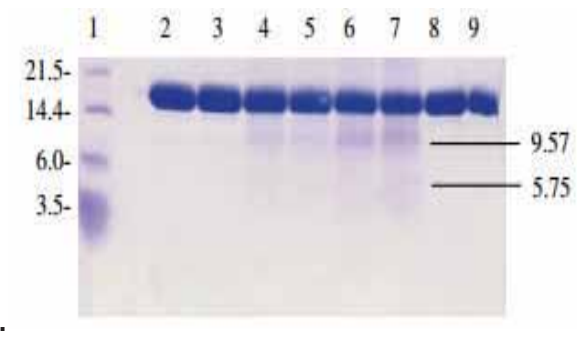

797 Figure 11. (A) Fluorescence spectra of Py-biotin $(2 \mu M)$ with increasing concentrations of CoHA (0798 $1.0 \mathrm{mM}$ ). Excitation wavelength is $342 \mathrm{~nm}$. (B) Quenching plots of the Py-biotin by CoHA, in buffer 799 (closed circles), and in the presence of avidin (squares). (C). Photocleavage of avidin by Py-Biotin 800 upon excitation at $342 \mathrm{~nm}$. Lane 1: Protein marker, Lane 2: Avidin, Lane 3: Avidin, Py-Biotin and 801 CoHA (Dark control), Lane 4-7: Avidin, Py-Biotin, and CoHA irradiated for 5, 10, 15, and 30 minutes, 802 803 Lane 8: Avidin and Py-Biotin, Lane 9: Avidin and CoHA irradiated for 30 minutes. Reproduced with permission from the Journal of Photochemistry and Photobiology B. ${ }^{44}$

\subsubsection{Photochemical Studies with Py-Biotin and Avidin}

806 Upon photoexcitation of pyrene at Py-Biotin's maximum absorption wavelength (342 nm), in 807 the presence of CoHA, the cleavage of avidin should occur near the Py-biotin binding site. The protein 808 solution $(15 \mu \mathrm{M}$ avidin), containing Py-biotin $(15 \mu \mathrm{M})$ and CoHA $(1 \mathrm{mM})$ in $50 \mathrm{mM}$ Tris-HCl buffer, 809 pH 7.0 (total volume $200 \mu \mathrm{L}$ ), was irradiated at $342 \mathrm{~nm}$ using a $150 \mathrm{~W}$ xenon lamp. A UV cutoff filter 
811 prepared under the same conditions, as described above, except that the solutions were protected from 812 light. All reaction mixtures were dried under reduced pressure and assayed on SDS/PAGE (Figure 813 11C). Two new photofragments were observed upon irradiation of avidin with Py-Biotin and CoHA

814 (Figure 11C) $)^{5}$ Yields of photoproducts increased steadily with irradiation time and reached a maximum 815 at 30 minutes, but the yields of the photoproducts were substantially less than noted with Py-Phe/BSA. 816 This outcome could be due to the substantially poor access of the probe to CoHA as inferred from 817 Figure 11B.

818 To test if Py-Biotin binds to avidin at the biotin binding site, competitive binding was studied 819 by mixing pure d-biotin with avidin/Py-Biotin before performing the photoreaction. If the binding sites 820 of d-biotin and Py-Biotin are the same, d-biotin should compete for the binding and may displace it. In 821 the inhibition study, the photoreactions were performed as above but d-biotin (60 $\mathrm{mM})$ was mixed with 822 the protein solution for 15 minutes prior to addition of Py-biotin (15 mM) and CoHA (1 mM). The 823 solutions were then irradiated at $342 \mathrm{~nm}$ as described above and products analyzed by SDS/PAGE. The 824 Py-Biotin photoreaction was suppressed by biotin substantially (data not shown), supporting the idea 825 that the probe binds at the biotin binding site, in a competitive manner. ${ }^{5}$

\section{4.2.2.4 Sequencing Studies}

827 Amino acid sequencing analysis of the photochemical fragments from avidin/Py-Biotin 828 indicated that the peptide is cleaved between Thr77 and Val78, which is known to be in proximity to 829 the biotin binding site ${ }^{5}$. This was confirmed by docking studies where a unique binding site was 830 noticed, described below.

831

832

833

834 835

\subsubsection{Computational Modeling}

The docking results are shown in Figure 12, and Py-Biotin had a binding energy of -10 kcal/mol. Various residues show potential hydrogen bonding, specifically Asn12, Ser16, Tyr33, Thr35 and Asn118 with the probe. The distance between the pyrene chromophore (edge) to Thr77 was $10 \AA$, which is in reasonable proximity for the photocleavage to occur at Thr 77 and Val 78. 
836

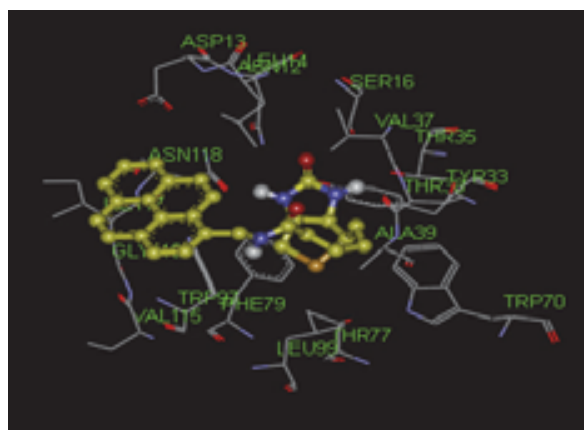

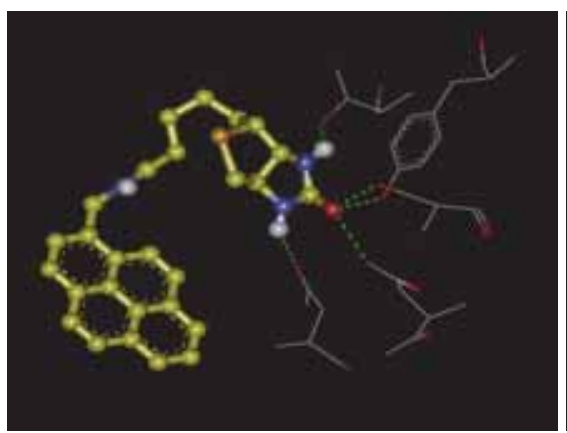

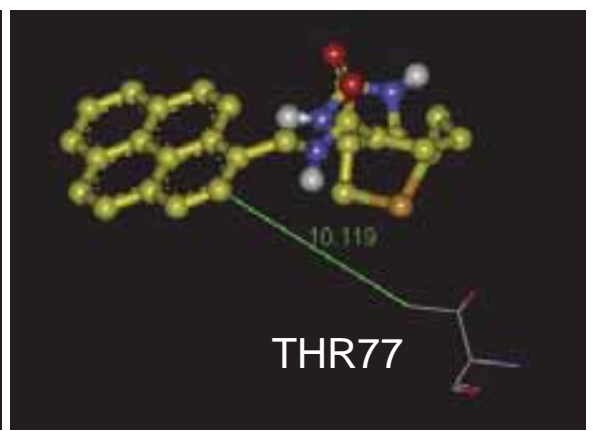

837 838

839

840

841

842

843

844

845

846

847

848

849

850

851

852

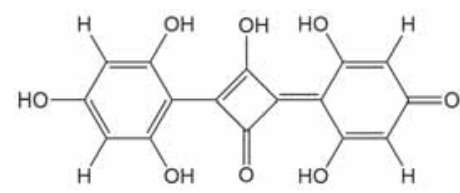

\subsection{Squaraine Dyes} of their interactions with proteins.

Figure 12. Docking of Py-Biotin with Avidin and residues at the binding site are within good proximity to the observed cleavage site.

Squaraine dyes are a class of photostable organic molecules that have diverse applications including imaging, sensing and, nonlinear optics. ${ }^{2727}$ These dyes typically have zwitterionic structures that are resonance stabilized. ${ }^{27}$ The squaraine dyes discussed here are bis(2,4,6-trihydroxyphenyl) squaraine $(\mathrm{D} 101)^{45}$, bis(3,5-dibromo-2,4,6-trihydroxyphenyl) squaraine(D103), or bis(3,5-diiodo2,4,6-trihydroxyphenyl) squaraine) D105 (Scheme 6). ${ }^{46,47}$ The halo-derivatives (D103 and D105), might undergo photodecomposition to generate the corresponding halogen radicals, which then could induce protein cleavage at the squaraine dye binding site. Thus, this class of dyes provided us a different avenue to test protein photocleavage reactions. Much like Py-Phe and its derivatives, changing the substituent on the ring systems changed the absorption and emission properties of the dye, and due to their high sensitivity to the environment, the three dyes differed significantly in terms
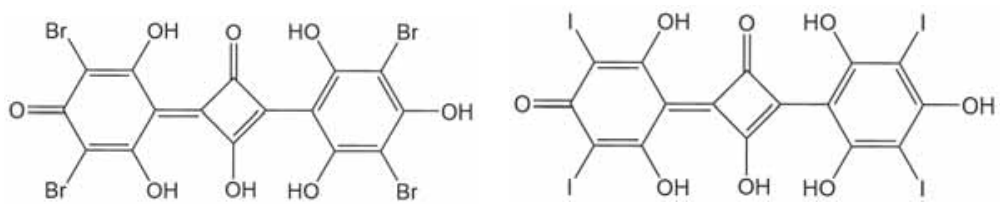

Scheme 6. Squaraine dyes under study (from left to right, D101, D103, and D105).

854

855

4.3.1 Photophysical studies

856 

860 quenching and increasing their fluorescence intensities.

861

A.

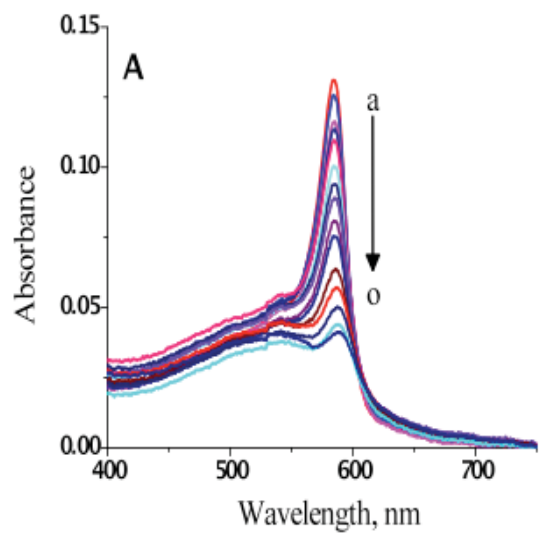

B.

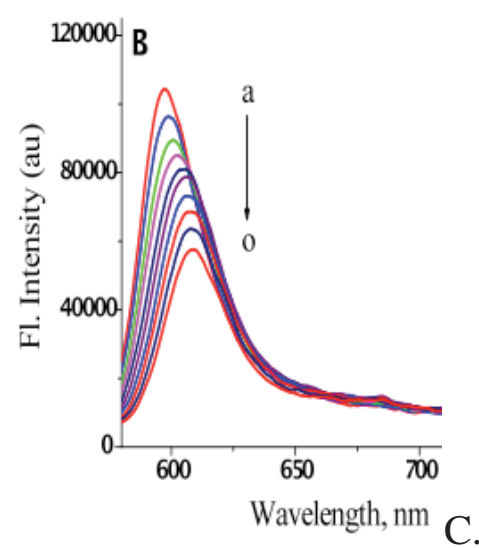

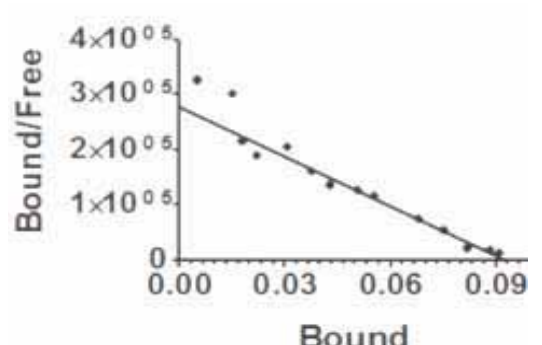

C.

862 Figure 13. (A) Absorption titration of D101 (1.1 $\mu \mathrm{M}$ in 2\% v/v ethanol-water mixture, pH 8.4) with 863 lysozyme (0 to $7.9 \mu \mathrm{M})$. (B) Fluorescence titration of $1.1 \mu \mathrm{M} \mathrm{D101} \mathrm{(2 \%} \mathrm{(v/v)} \mathrm{ethanol)} \mathrm{with} \mathrm{lysozyme} \mathrm{(0}$ 864 to $7.9 \mu \mathrm{M})$ in phosphate buffer $\mathrm{pH} 8.4,575 \mathrm{~nm}$ excitation. (C) Scatchard plot obtained from the 865 absorption titration shown in panel A, which indicated a binding constant of $3 \times 10^{6} / M$.

\section{6}

867

868

869

870

871

872

873

874

875

876

877

878

When increased concentrations of lysozyme $(0$ to $7.9 \mu \mathrm{M})$ were titrated into a solution of D101 $(1.1 \mu \mathrm{M}$, in $2 \mathrm{v} / \mathrm{v} \%$ ethanol-water mixture, $\mathrm{pH} 8.4)$, there has been substantial decrease in absorbance as well as fluorescence (Figure $13 \mathrm{~A}){ }^{28,3449}$ The interaction was further confirmed by constructing a binding isotherm using the Scatchard equation (eq. 1), ${ }^{36}$ and the corresponding binding plot is shown in Figure $13 \mathrm{C}$. Best fit to the data indicated a single binding site with a binding constant of $3 \times 10^{6} / \mathrm{M}$ for D101.

Similar spectral changes were noted for D103 (5 $\mu \mathrm{M}$ in 2\% ethanol-water mixture, $\mathrm{pH}$ 6.4) and D105 $(1.4 \mu \mathrm{M}, 2 \% \mathrm{v} / \mathrm{v}$ ethanol in water, $\mathrm{pH}$ 6.4) titrations with lysozyme (0 to $6.2 \mu \mathrm{M})$, as above, and the corresponding Scatchard plots obtained from the absorption titrations indicated binding constants of $1.0 \times 10^{8} / \mathrm{M}$ and $2.0 \times 10^{6} / \mathrm{M}$ for D103 and D105, respectively. Thus, the affinity was substantially higher for D103 than D101 or D105, but all three dyes indicated hypochromism and fluorescence quenching on binding to lysozyme. 
Absorbance spectra of the squaraine dyes $(30 \mu \mathrm{M})$ mixed with BSA $(30 \mu \mathrm{M})$ were monitored.

880 There have been immediate changes in the absorbance when the probes bind to the protein (in $10 \mathrm{mM}$ 881 sodium phosphate buffer, $50 \mathrm{mM} \mathrm{NaCl}, \mathrm{pH} 7.4$, Figure 15), but these changes continued further for up 882 to $4 \mathrm{~h}$, after which no substantial changes were detected. The peak wavelength of D101 blue shifted by 883 $13 \mathrm{~nm}$ to $582 \mathrm{~nm}$, immediately after mixing. The shoulder at $500 \mathrm{~nm}$ also blue shifted approximately 884 $20 \mathrm{~nm}$ and all peaks decreased in intensity, as a function of incubation time (data not shown) Thus, the 885 initial binding is followed by further interaction with BSA, which was not the case with the Py-Phe 886 derivatives described above.

887
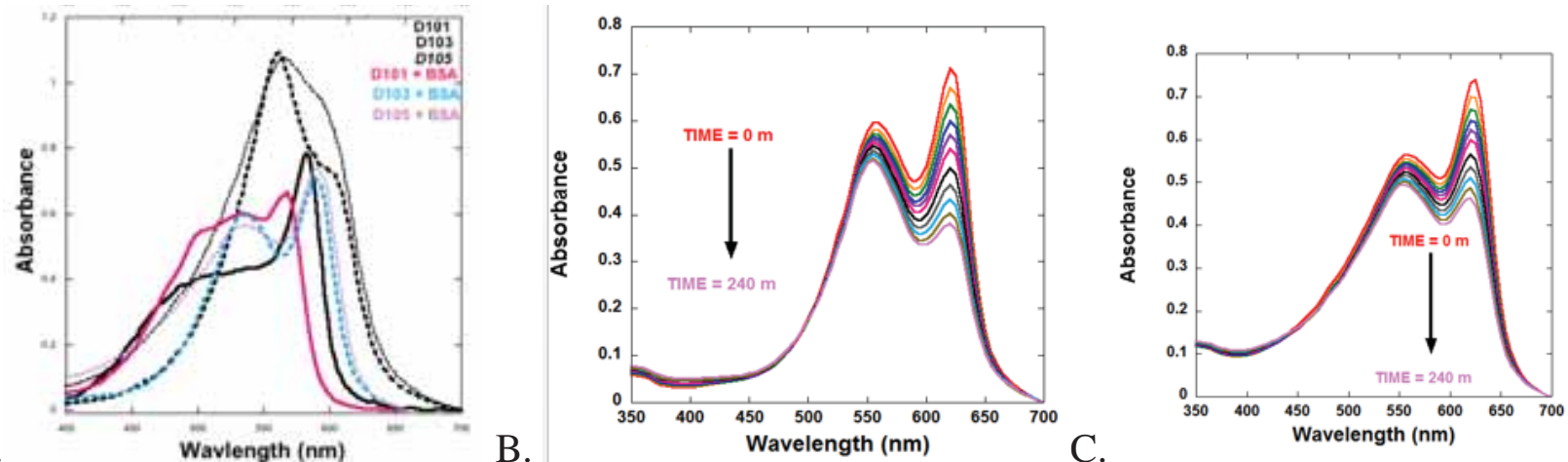

Figure 14. (A) The shift in absorbance of the squaraine dyes bound to BSA (D101-BSA pink solid, 889 D103-BSA blue dashed, D105-BSA purple dotted lines) compared to those of the dyes in $10 \mathrm{mM}$ 890 phosphate 50 mM sodium chloride buffer pH 7.4 (D101 black solid, D103 black dashed, D105 black 891 dotted lines). (B) Absorbance of $30 \mu \mathrm{M} D 103$ in the presence of $30 \mu \mathrm{M}$ BSA in $10 \mathrm{mM}$ phosphate 50 892 mM sodium chloride buffer pH 7.4 as a function of time. (C) Absorbance of $30 \mu M$ D105 in the 893 presence of $30 \mu \mathrm{M}$ BSA in $10 \mathrm{mM}$ phosphate $50 \mathrm{mM}$ sodium chloride buffer pH 7.4 as a function of 894 time. Time 0 in these panels is the spectra immediately after mixing the dye and BSA, which is 895 substantially different from that of the free dye.

896

897

The absorption peaks of D103 and D105 at 550 nm decreased in intensity while a new peak at 898 $620 \mathrm{~nm}$ appeared for both D103-BSA and D105-BSA samples (Figure $14 \mathrm{~B}, \mathrm{C}$ ). The $625 \mathrm{~nm}$ peak 899 decreased at a faster rate than $550 \mathrm{~nm}$ peak. Dilution of the dye-BSA solutions did not restore the 900 absorbance spectra to their original profiles, which suggested that the changes are not due to simple 901 902 physical association, as seen with Py-Phe derivatives. Control experiments of the squaraine dyes dissolved in buffer under identical conditions revealed a decrease in absorbance similar to that 
903 observed with BSA, which indicated an eventual chemical reaction of the dye with the solvent or the 904 protein. These observations were further tested in CD and precipitation studies.

905

906

907

908

909

910

911

912

913

914

A

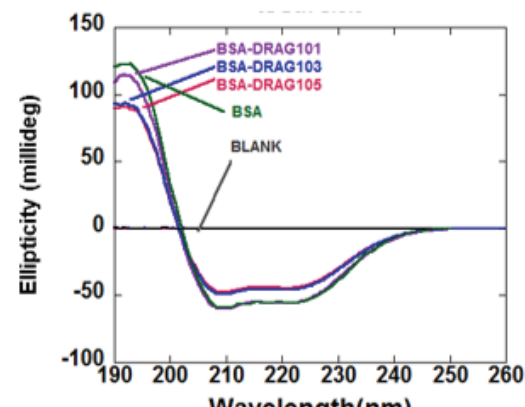

Wavelength(nm)

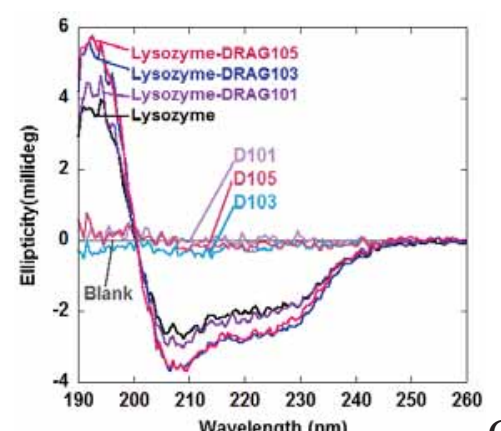

B.

\subsubsection{Circular Dichroism Studies}

There has been no significant change in the deep UV CD of BSA (Figure 15A) when the dyes were titrated, which indicated no significant distortion of the protein structure upon probe binding. Binding of these probes to lysozyme also did not distort the protein structure to any significant extent, only small changes have been noted (Figure 15B). On the other hand, induced CD bands were noted upon binding of the squaraine dyes $(30 \mu \mathrm{M})$ to lysozyme (60 $\mu \mathrm{M}$, phosphate buffer), in the visible region, far from the UV CD bands of the protein (Figure 15C). That is, the binding places the chromophores in the asymmetric environment and this trigger induced CD in the transitions that correspond to the dye absorption bands in the visible region. Intense induced $\mathrm{CD}$ bands were noted for D103 and D105 but that of D101 has been very weak.

916 Figure 15. (A) UV CD spectra of BSA-squaraine dyes, D101-BSA (purple), D103-BSA (blue) and

917 D105-BSA (pink) and BSA (green) in phsophate buffer. Spectra of D10X in buffer are shown but could 918 not be distinguished from that of the baseline. (B) UV CD spectra of lysozyme-squaraine dyes in 919 phsophate buffer, D101-lysozyme (purple), D103-lysozyme (blue), and D105-lysozyme (pink) and 920 those of free dyes in phosphate buffer, D101 (light purple), D103 (light blue) and D105 (light pink). 921 (C) Induced CD of the squaraine dyes bound to lysozyme in the phsophate buffer, D101/lysozyme 922 (pink), D103/lysozyme (purple) and D105/lysoyzme (blue). 


\subsubsection{Enzyme Inhibition and Binding Studies with Individual Amino Acids}

Binding of the squaraine dyes to lysozyme could inhibit its activity, if the photoreagent binds at or near the active site of the enzyme. This possibility was tested by examining lysozyme-induced degradation of bacterial cells (micrococcus lysodeikticus) by reported methods. ${ }^{49}$ Lysozyme activity was not inhibited by the addition of D101 or D103 but there has been significant inhibition by D105 (Figure 16B, pink). Thus, one concludes that D101 and D103 did not block the active site or bind to residues at the active site, but D105 is likely blocking access to the active site of the enzyme or reacted with active site residues, thus inhibiting enzyme activity to a substantial extent.

To test this hypothesis, we examined the reaction of several amino acids with the squaraine dyes by fluorescence spectroscopy (Figure 16A). As increasing amounts of cysteine were titrated into a solution of D101, a decrease in fluorescence emission at $600 \mathrm{~nm}$ was observed indicating interaction between D101 and cysteine. Covalent interaction was confirmed by separating the dye bound to the protein by acetone precipitation of lysozyme-D10X solutions. All three dyes are soluble in acetone and if the dye is covalently bound to the protein then acetone precipitation of the protein would not release the dye from the protein into the solvent. On the other hand, if the dye is only adsorbed onto the protein by non-covalent interactions, then it will be released into acetone solvent. Samples containing 1:1 mole ratio of lysozyme and the squaraine dyes were treated with acetone, incubated at $-20^{\circ} \mathrm{C}$ for one hour then centrifuged to remove the protein, and the absorption spectra of the supernatant recorded. Control experiments were carried out where the dye solutions were treated in a similar fashion in the absence of the protein, and the corresponding spectra recorded. From these data, the dye concentrations in acetone were estimated and shown in Figure 16C. 


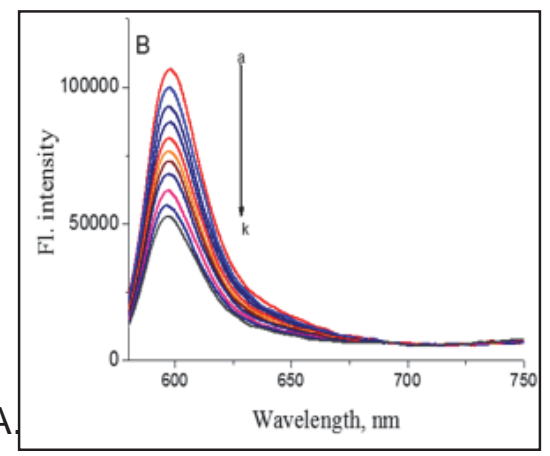

A.

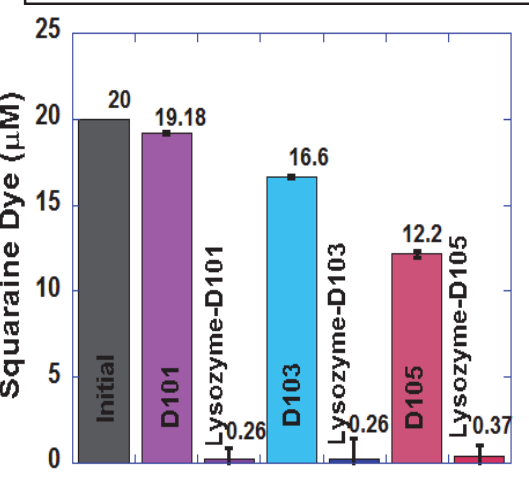

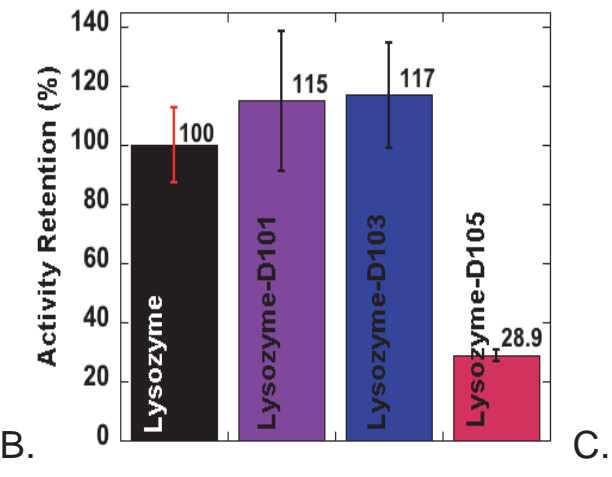

946

947

948

949

950

951

952

953

954

955

956

957

958

959

960

961

962

Figure 16. (A) Fluorescence spectra of D101 with increasing concentrations of cysteine (0 $\mu M$, (red) to $8.5 \mu \mathrm{M},($ purple $))$ in $2 \%$ ethanol $(v / v)$ in phosphate buffer, upon excitation at $560 \mathrm{~nm}$. (B). Enzymatic activity of lysozyme monitored after dye binding, in phosphate buffer. Activities of lysoyzme (no dye, black), lysozyme-D101 (purple), lysozyme-D103 (blue), and lysozyme-D105 (pink). (C). Concentrations of the squaraine dyes in supernatant after acetone precipitation, D101 (light purple), D101-lysozyme (dark purple), D103 (light blue), D103-lysozyme (dark blue), D105 (light pink) and D105-lysozyme (dark pink).

The acetone precipitation showed considerable drop in dye concentration in the acetone phase, after precipitation, for all the three dye samples (Figure 16C), and recovery of the dyes in the absence of the protein has been substantial. These data confirmed that the three squaraine dyes bind to lysozyme by covalent adduction to particular residues, and these could not be released by acetone precipitation of the protein. Thus, the protein-bound probes were tested for photocleavage reactions to identify the probe binding sites on the protein.

\subsubsection{Photochemical Properties}

\subsubsection{SDS/PAGE}


A mixture of lysozyme, CoHA and squaraine dyes in phosphate buffer were irradiated in RPR100 photoreactor, equipped with visible light, for $30 \mathrm{~min}$. The SDS/PAGE results are shown in Figure 17 and there have been substantial presence of at least one photoproduct when all three reagents are present (lanes 4 and 8). However, the control lanes that did not contain the squaraine dye (lanes 5 and 9) also indicated the same product band, which clearly indicated photocleavage due to CoHA. Indeed, we have previously reported the photocleavage of lysozyme by $\mathrm{CoHA}^{50}$ and current experiments showed that the squaraine dyes did not cleave lysozyme under these conditions.

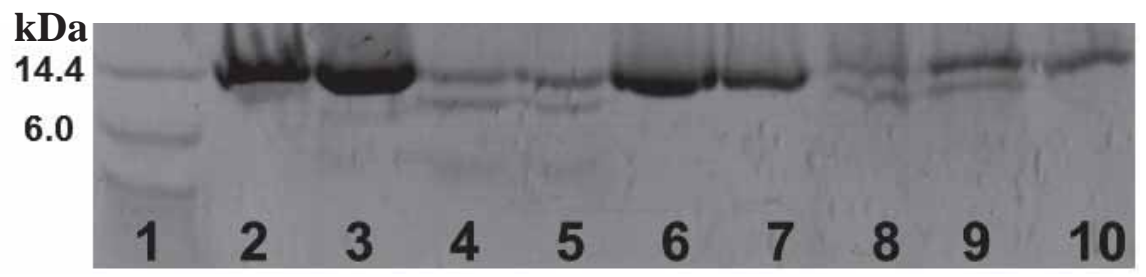

Figure 17. Photocleavage studies of D101 and D103 with lysozyme in $10 \mathrm{mM}$ sodium phosphate 50 mM sodium chloride buffer pH 7.4 after irradiation with white light. Lane 1, molecular weight markers. Lanes 2 - 10 contain $15 \mu$ M lysozyme, lanes 3,4,7 and 8 contained 5 mM CoHA, lanes 3-4,

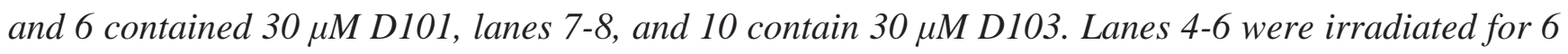
h, lanes 8-10 were irradiated for $12 \mathrm{~h}$. Lanes 3 and 7 were protected from light. Photocleavage 976 products of 11 and $5 \mathrm{kDa}$ are present in lanes 4, 5, 8 and 9.

977

978 small set of proteins and their photoreactions have been examined in sufficient detail. By far, most of the probes examined here were successful in inducing protein photocleavage with the exception of the squaraine dyes, which did not photocleave lysozyme.

\section{Other Contributions to the Field of Protein Photocleavage}

A number of other groups around the world have extended these design features, subsequent to our initial reports of the protein photocleavage investigations. A few representative examples will be mentioned here, briefly, to demonstrate the potential of the above methodology but this is not a thorough review of other work. Photoexcitation of anthraquinone and 2-hydroxymethylantraquinone 987 $(5-150 \mu \mathrm{M})$ with BSA $(15 \mu \mathrm{M})$ produced photocleavage. ${ }^{51}$ Samples were irradiated at $365 \mathrm{~nm}$, in $20 \%$ acetonitrile $50 \mathrm{mM}$ Tris-HCl, $\mathrm{pH}$ 7.0. SDS/PAGE showed no specific product bands but cleavage was 
989

990

991

992

993

994

995

996

997

998

999

1000

1001

1002

1003

1004

1005

1006

1007

1008

1009

1010

1011

1012

1013

1014

1015

1016

1017

1018

random. Anthraquinone weakly cleaved BSA while 2-hydroxymethlantraquinone significantly cleaved BSA but no yields were reported not cleavage sites identified. Further experiments with lysozyme (15 $\mu \mathrm{M})$ and derivatives (anthraquinone-triethylene glycol and anthraquinone-carbohydrate, 5-150 $\mu \mathrm{M}$ ) also resulted in photoreactions via reactive oxygen species generated during the reaction.

Photoexcitation of Phenol Red-modified 5,10,15,20-tetraphenylporphyrin (R-TPP, $25 \mu \mathrm{M}$ ) at $420 \mathrm{~nm}$ cleaved both BSA and lysozyme $(25 \mu \mathrm{M})$ in 3:1 PBS/DMS via singlet oxygen, but photoreaction yields and protein cleavage sites were not reported. ${ }^{52}$ The phenol red moiety in the probe was suggested to contribute to the binding affinity, amphiphilic character, and suppress aggregation. Binding constants of R-TPP reported with BSA was $8.49 \times 10^{4} \mathrm{M}^{-1}$ and with lysozyme has been $2.11 \times 10^{4} \mathrm{M}^{-1}$. This was further expanded with derivatives of rhodamine-3-acetic acid (RhD-TPP and RhDCOOH-TPP $)^{53}$ to cleave BSA $(2 \mu \mathrm{M})$ using radiation $<420 \mathrm{~nm}$. Binding constants for both rhodamine derivatives were reported to be $4.67 \times 10^{4} \mathrm{M}^{-1}$ and $4.46 \times 10^{4} \mathrm{M}^{-1}$, respectively. ${ }^{53}$

An interesting example is the protein photocleavage of the transcription factor, ER- $\alpha$ by 2Phenylquinoline, 2-phenylquinoline-estradiol and 2-phenylquinoline-4-hydroxytamoxifen. ${ }^{54}$ The estradiol and tamoxifen are biologically active for breast cancer or osteoporosis treatments. 2-phenyl quinolone degraded proteins with long wavelength UV light, under $\mathrm{pH}$ neutral conditions. Excitation at $365 \mathrm{~nm}$ of the quinolone probes generates a reactive oxygen species and led to non-specific photocelavage of ER- $\alpha$. But the fragments were too small in quantity to be detected by MALDI-TOF or SDS-PAGE. ${ }^{54}$ Upon incubation with MCF-7 cells and irradiation at $365 \mathrm{~nm}$, both quinoline derivatives inhibited cell growth in a dose dependent manor.

\section{Conclusions}

A number of small organic molecules have been designed, synthesized and tested for their binding to proteins, which indicated several examples where the photoreaction has been successfully induced. The binding affinities, however, depended on probe structure in a complex manner, and could not be rationalized by any simple model. While their affinities differed, they all responded substantially on binding to the protein, in terms of their photophysical properties. Protein binding resulted in substantial changes in the absorption and fluorescence spectra, and the data have been quantified using Scatchard equation. In all the cases examined here, except for Py-Phe/BSA, all systems indicated a single binding site with moderate to high affinities. Binding to the protein also buried the chromophore in the protein matrix and its access to the solvent was successfully probed in 
1019 fluorescence quenching studies by CoHA. Furthermore, the degree of protection offered by the protein 1020 against quenching with CoHA roughly correlated inversely with the yield of the photocleavage 1021 reaction, yields with lysozyme being higher than with BSA. Thus, some access to the bound 1022 chromophore by CoHA was essential to initiate the photoreaction.

The newly created N-terminus of the photoproduct was amenable to conventional sequencing 1024 studies, which is an important result with ramifications about the application of these photoreagents for 1025 biochemical studies. However, the newly created C-terminus was not sequenceable, but these 1026 constraints helped us in narrowing down the possible mechanistic schemes that could be devised. Another significant observation was that many of the photoreagents shared the same cleavage site on BSA and lysozyme, with some exceptions. This could be because they all had the large hydrophobic pyrenyl group but the side chain played an important role. Longer chains allowed the probe to access residues that are farther and new cleavage sites were noted. Along the same lines, the attachment of biotin in the side chain allowed Py-Biotin to be directed to the biotin binding site and this is likely due to the higher affinity of biotin to its binding site on avidin when compared to that of the pyrenyl moiety.

Computer docking studies, conducted recently, provided strong support for the photocleavage and sequencing studies. The docked structures indicated good proximity of the photoreagent to the observed cleavage site, and the experimental data have validated the success of the computer modeling. This indeed, is surprising, given the uncertainties involved in the experiment as well as in the computational modeling. In future studies, computer modeling may be used in an iterative manner, to target specific sites on a given protein, followed by experiments to verify if a predicted site could be hit with a designed probe. We are not there yet, but with increased computational power and the availability of reliable and sophisticated algorithms should make this a viable strategy to photocleave proteins at desired sites.

In summary, the photoreagent design should consider several factors, such as potential binding sites on the target protein, desired structural features of the photoreagent to bind at the binding site and 1045 the excited state properties of the chromophore as well as the quencher. Attachment of the quencher to the chromophore would be the next step and this would remove the requirement that the probe be accessible to the solvent for efficient quenching to initiate the photochemistry. The excited state need to live long enough to induce the desired reaction at the protein binding site but it also should have the 
1049 necessary chemical reactivity. CoHA played an important role in the examples presented here, where 1050 it generated a long lived radical intermediate from the pyrenyl chromophore, which successfully 1051 induced the photocleavage of the protein backbone. There could be other possible intermediates that 1052 would cleave the protein backbone, selectively and efficiently. This type of photochemical control of I053 biological macromolecular chemistry is likely to be interesting in the near future.

\section{7. Acknowledgments}

1055 We thank the National Science Foundation for the financial support of the work (EAGER DMR1056 1441879) and the University of Connecticut OVPR for the Research Excellence Award. We also 1057 thank Ms. D. Iyer for technical assistance with some spectral studies on squaraine dyes.

${ }^{1}$ Kumar, C.V. and Buranaprapuk, A. Site-specific photocleavage of proteins, Angew. Chem. Int. Ed. Engle. 36 (1997) 2085-2087.

${ }^{2}$ A. Buranaprapuk, Y. Malaikaew, J. Svasti, C. V. Kumar, Chiral protein scissors activated by light: recognition and protein photocleavage by a new pyrenyl probe, J. Phys.Chem. B. 112 (2008) 9258-9265.

${ }^{3}$ C. V. Kumar, A. Buranaprapuk, G. J. Opiteck, M. B. Moyer, S. Jockusch, N. J. Turro, Photochemical protease: site-specific photocleavage of hen egg lysozyme and bovine serum albumin, Proc. Natl. Acad. Sci, USA. 95 (1998) 10361-10366.

${ }^{4}$ C. V. Kumar, J. Thota, and A. Buranaprapuk, Protein Scissors: Photocleavage of Proteins at Specific Locations, Proc. Natl. Acad. Sci. (India), 114 (2003) 579-592

${ }^{5}$ P. Malaikaew, J. Svasti, C. V. Kumar, A. Buranaprapuk, Photocleavage of avidin by a new pyrenyl probe, $J$. Photochem. Photobio., B. 102 (2011) 251-255.

${ }^{6}$ A. Buranaprapuk, C. V. Kumar, S. Jockusch, and N. J. Turro, Photochemical protein scissors: role of aromatic residues on the binding affinity and photocleavage efficiency of pyrenyl peptides, Tetrahedron 56 (2000) 70197025 .

${ }^{7}$ C. V. Kumar, and A. Buranaprapuk, Tuning the selectivity of protein photocleavage: spectroscopic and photochemical studies, J. Am. Chem. Soc. 121 (1999) 4262-4270.

${ }^{8}$ C. V. Kumar, M. J. Novak, K. B. Benson, C. Baveghems, B. K. Thilakarathne, B. S. Stromer, F. M. Ross, Toward the design of bio-solar cells: high efficiency cascade energy transfer among four donor-acceptor dyes self-assembled in a highly ordered protein-DNA matrix, RSC Adv. 5 (2015) 72416-72422.

${ }^{9}$ M. Duff, C. V. Kumar. Toward building artificial light harvesting complexes: Enhanced singlet-singlet energy transfer between donor and acceptor pairs bound to albumin, J. Photochem. Photobiol. Sci., 7, (2008) 15221530 .

${ }^{10}$ Our oil drop model of a protein postulated two decades ago is supported by a recent study here: M. Benach, L. Konieczny, I. Roterman, The fuzzy pol drop model based on hydrophobicity density distribution, generalizes the influence of water environment on protein structure and function, J. Theor. Biol. 359 (2014) 6-17.

${ }^{11}$ C. V. Kumar, and J. Thota Inorganic Protein Scissors: Photocleavage of lysozyme by Co(III) complexes, Inorg. Chem., 44 (2005) 825- 827

${ }^{12}$ Concepts of inorganic photochemistry'. Eds. Arthur W. Adamson, Paul D. Fleischauer. John Wiley \& Sons Australia, 1975. 
${ }^{13}$ C. V. Kumar, W. B. Tan, and P. W. Betts, Photocleavage of DNA with visible light, J. Inorg. Biochem., 68 (1997) 177.

${ }^{14}$ M.R. Duff and C.V. Kumar. Site Specific photocleavage of proteins by uranyl ions. Angwe. Chem. 45 (2006) 137-139.

${ }^{15}$ B. Jityuti, T. Liwporncharoenvong, , A. Buranaprapuk. Use of molybdenum (VI) complex as an artificial protease in protein photocleavage. J. Photochem. Photobio., B. 126 (2013) 55-59.

${ }^{16}$ A. Buranaprapuk, S. P. Leach, C.V. Kumar, J.R. Bocarsly. Protein cleavage by transition metal complexes bearing amino acid substituents. Biochim. Biophys. Acta. 1387 (1998) 309-316.

${ }^{17}$ G. J. Quinlan, G. S. Martin, and T. W. Evans, albumin; Biochemical properties and therapeutic potential, Hepatology, 41 (2011) 1211-1219.

${ }^{18}$ Peters TJ. All about Albumin: Biochemistry, Genetics, and Medical Applications. San Diego: Academic Press; 1995.

${ }^{19}$ Jimenez, M.C., Miranda, M.A., Vaya, I. Triplet excited states as chiral reporters for the binding of drugs to transport proteins. J. Am. Chem. Soc. 127 (2005) 10134-10135.

${ }^{20}$ PDB ID: 3V03. Majorek, K.A., Porebski, P.J., Dayal, A., Zimmerman, M.D., Jablonska, K., Stewart, A.J., Chruszcz, M., Minor, W. Structural and immunologic characterization of bovine, horse, and rabbit serum albumins. Mol. Immunol. 52 (2012) 174-182.

${ }^{21}$ PRD ID: 1DPX. M. S. Weiss, G. J. Palm, R. Hilgenfel, Crystallization, structure solution and refinement of hen egg-white lysozyme at pH 8.0 in the presence of MPD, Acta Crystallogr., Sect. D. 56 (2000) 952-958.

${ }^{22}$ PDB ID: 2AVI. O. Livnah, E. A. Bayer, M. Wilchek, J. L. Sussman, Three-dimmensional structures of avidin and the avidin-biotin complex, Proc. Natl. Acad. Sci. USA. 90 (1993) 5076-5080.

${ }^{23}$ Worthington K. and Worthington, V. Worthington enzyme manual. 2011. Worthington Biochemical Corporation.

${ }^{24}$ Weiss, M.S., Palm, G. J., Hilgenfel, R. Crystallization, structure solution and refinement of hen egg-white lysozyme at pH 8.0 in the presence of MPD. Acta Crystallogr., Sect. D. 56 (2000) 952-958.

${ }^{25}$ P. S. Stayton, Freitag, L. A. Klumb, A. Chilkoti, V. Chu, J. E., Penzotti, R. To, D. Hyre, I. Le trong, T. P. Lybrand and R. E. Stenkamp., Streptavidin-biotin binding energetics, Biomol. Eng., 31 (1999) 39-44.

${ }^{26}$ C. M. Dundas, D. Demonte, and S. Park, Appl. Microbiol. Biotechnol., 97 (2013) 9343-53.

${ }^{27}$ S. Sreejith, P. Carol, P. Chirthra, and A. Ajayaghosh, Squaraine dyes: a mine of molecular materials, $J$. Mater. Chem. 18 (2008) 264-274.

${ }^{28}$ V. S. Jisha,, K. T. Arun, M. Hariharan, D. Ramaiah, Site-selective binding and dual mode recognition of serum albumin by a squaraine dye, J. Am. Chem. Soc. 128 (2006) 6024-6025.

${ }^{29}$ F. M. Winnik, Photophysics of preassociated pyrenes in aqueous polymer solutions and in other organized media, Chem. Rev., 93 (1993) 587-614.

${ }^{30}$ A. Williams, and I. T. Ibrahim, Carbodiimide chemistry: recent advances, Che. Rev., 81 (1981) 589-636.

${ }^{31}$ Kumar, C.V. and Buranaprapuk, A. Site-specific photocleavage of proteins, Angew. Chem. Int. Ed. Engle. 36 (1997) 2085-2087. Copyright Wiley-VCH Verlag GmbH \& Co. KGaA. Reproduced with permission.

${ }^{32}$ C. V. Kumar, and A. Buranaprapuk, Tuning the selectivity of protein photocleavage: spectroscopic and photochemical studies, J. Am. Chem. Soc. 121 (1999) 4262-4270. Copyright (1999) American Chemical Society. 
${ }^{33}$ C. V. Kumar, J. Thota, and A. Buranaprapuk, Protein Scissors: Photocleavage of Proteins at Specific Locations, Proc. Natl. Acad. Sci. (India), 114 (2003) 579-592. Copyright (2002) National Academy of Sciences.

${ }^{34}$ A. Buranaprapuk, and C. V. Kumar, Chiral Protein Scissors: Improved photocleavage Efficiency, Lett. In Org. Chem, 2 (2005) 554.

${ }^{35}$ C. V. Kumar, A. Buranaprupak, H.C. Sze, S. Jockusch, and N. J. Turro, Chiral protein scissors: High enantiomeric selectivity for binding and its effect on protein photocleavage efficiency and specificity, Proc. Natl. Acad. Sci, USA. 99 (2002) 5810-5815.

${ }^{36}$ Scatchard, G. The attractions of proteins for small molecules and ions, Ann. N.Y. Acad. Sci., 51 (1949) 660672.

${ }^{37}$ A. Buranaprapuk, C. V. Kumar, S. Jockusch, and N. J. Turro, Photochemical protein scissors: role of aromatic residues on the binding affinity and photocleavage efficiency of pyrenyl peptides, Tetrahedron 56 (2000) 70197025 .

${ }^{38}$ C. V. Kumar, A. Buranaprupak, H.C. Sze, S. Jockusch, and N. J. Turro, Chiral protein scissors: High enantiomeric selectivity for binding and its effect on protein photocleavage efficiency and specificity, Proc. Natl. Acad. Sci, USA. 99 (2002) 5810-5815. Copyright (2002) National Academy of Sciences.

39 “Modern Molecular Photochemistry' by N. J. Turro, University Science Books, (1991).

${ }^{40}$ Kumar, C. V., A. Buranaprapuk, and Sze, H.C. Large chiral discrimination of a molecular probe by bovine serum albumin, Chem. Comm., (2001) 297-298.

${ }^{41}$ Schagger, H., Nature Protocols, 1 (2006) 16-22.

${ }^{42}$ H. Steen, and M. Mann, The abc's (and XYZ's) of peptide sequencing, Nature reviews Molecular Cell Biology, 5 (2004) 699-711.

43 "Publisher's note: Sir John A. Pople, 1925-2004". J. Computational Chem. 25 (2004): fmv-vii. 2004.

${ }^{44}$ A. Buranaprapuk, Y. Malaikaew, J. Svasti, C. V. Kumar, Chiral protein scissors activated by light: recognition and protein photocleavage by a new pyrenyl probe, J. Phys.Chem. B. 112 (2008) 9258-9265. Copyright 2011 Journal of Photochemistry and Photobiology B: Biology.

${ }^{45}$ A. Triebs, K. Jacob, Angew. Chem., Int. Ed. 4 (1965) 694-695

${ }^{46}$ D. Ramaiah, A. Joy, N. Chandrasekhar, N. V. Eldho, S. Das, M. V. George, Photochem. Photobiol. 65 (1997) 783-790

${ }^{47}$ K. T. Arun, D. T. Jayaram, R. R. Avirah, D. Ramaiah, $\beta$-Cyclodextrin as a Photosensitizer Carrier: Effect on Photophysical Properties and Chemical Reactivity of Squaraine Dyes, J. Phys. Chem. B, 115 (2011) 7122-7128.

${ }^{48}$ D. Ramaiah, I. Eckert, K. T. Arun, L. Weidenfeller, B. Epe, Photochem. Photobiol. 76 (2002) 672-677.

${ }^{49}$ Shugar, D. Biochim Biophys Acta 8 (1952) 302.

${ }^{50}$ J. Thota, K. Bandara, and C. V. Kumar, Photochemical Protein Scissors: Co(III) complexes, J. Photochem. Photobio. Sci., 7 (2008) 1530-39.

${ }^{51}$ Suzuki, A., Hasegawa, M., Ishii, M., Matsumura, S., and Toshima, K. Antraquinone derivatives as a new family of protein photocleavers. Bioorg. Med. Chem. Lett. 15 (2005) 4624-4627.

${ }^{52}$ Jiang G.Y., Lei, W., Zhou, Q., Hou, Y., Wang, X., and Zhang B. A new phenol red-modified porphyrin as efficient protein photocleaving agent. Phys. Chem. Chem. Phys. 12 (2010) 12229- 12236

${ }^{53}$ Jiang, G.Y., Lei, W.H., Zhou, Q.X., Hou, Y.J., Wang, X.S. Small change in structure leads to large difference in protein photocleavage: two porphyrins bearing rhodamine-based pendants. Photochem. Photobiol. Sci. 11 (2012) 715-723. 
${ }^{54}$ Tsumura K., Suzuki, A., Tsuzuki, T., TanimotoS., Kaneko, H., Matsumura, S., Imoto, M., Umezawa, K., Takhashi, D., and Toshima, K. Molecular design, chemical synthesis, and biological evaluation of agents that selectively photo-degrade the transcription factor estrogen receptor- $\alpha$. Org. Biomol. Chem. 9 (2011) 63576366. 